Universidade de São Paulo
Faculdade de Medicina de Ribeirão Preto

\title{
INFLUÊNCIA DA MASTECTOMIA UNILATERAL NO EQUILÍBRIO ESTÁTICO E NA MARCHA
}
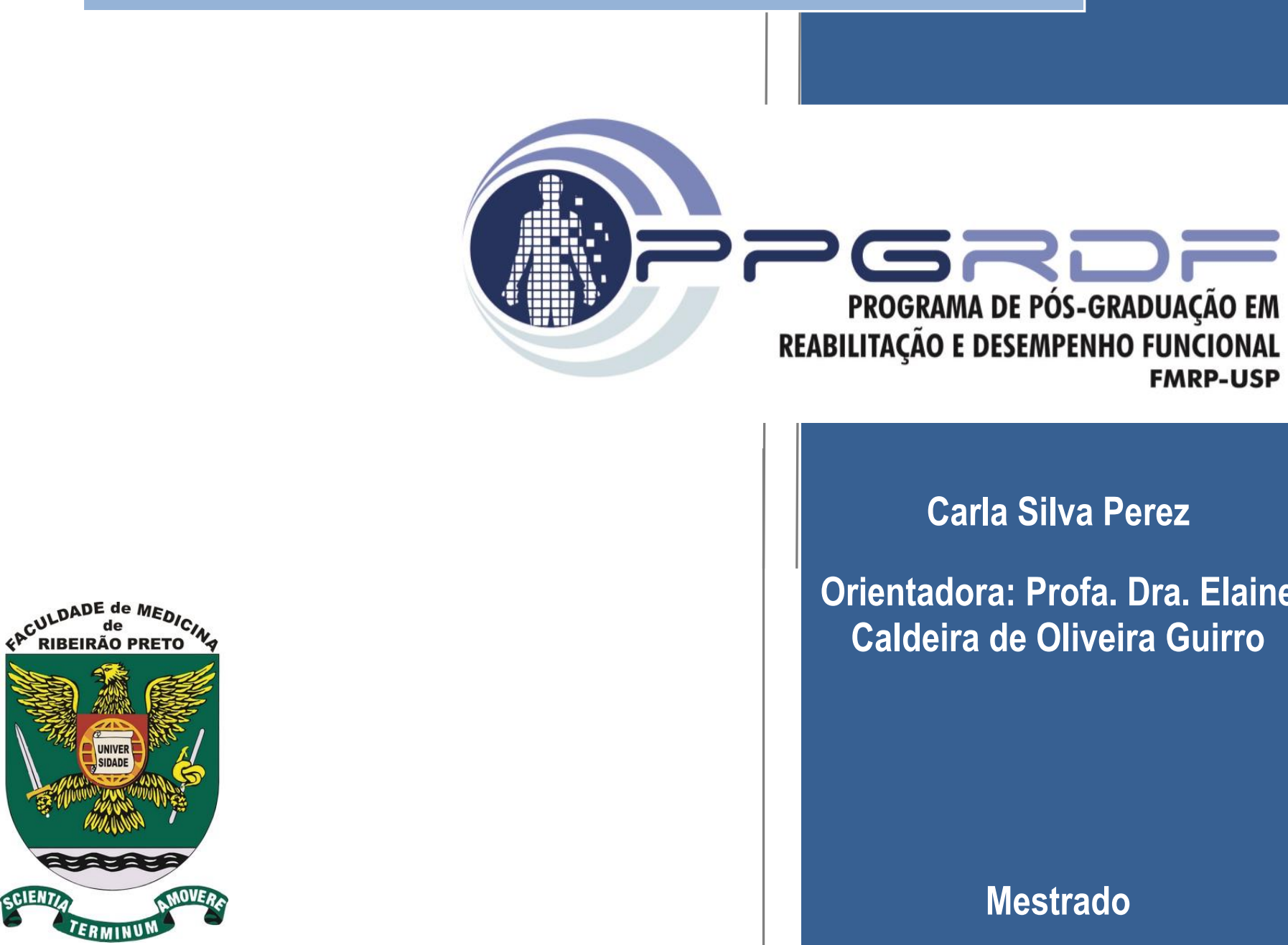

\section{Carla Silva Perez}

Orientadora: Profa. Dra. Elaine Caldeira de Oliveira Guirro 


\section{UNIVERSIDADE DE SÃO PAULO}

\section{FACULDADE DE MEDICINA DE RIBEIRÃO PRETO}

\section{CARLA SILVA PEREZ}

Influência da mastectomia unilateral no equilíbrio estático e na marcha

Ribeirão Preto

2015 


\title{
CARLA SILVA PEREZ
}

Influência da mastectomia unilateral no equilíbrio estático e na

\author{
marcha
}

\section{VERSÃO CORRIGIDA}

Dissertação apresentada ao Programa de PósGraduação em Reabilitação e Desempenho Funcional - FMRP/USP, pelo Departamento de Biomecânica, Medicina e Reabilitação do Aparelho Locomotor para obtenção do Título de Mestre em Ciências.

Área de concentração: Fisioterapia

Orientadora: Profa. Dra. Elaine C. O. Guirro

\section{Ribeirão Preto}




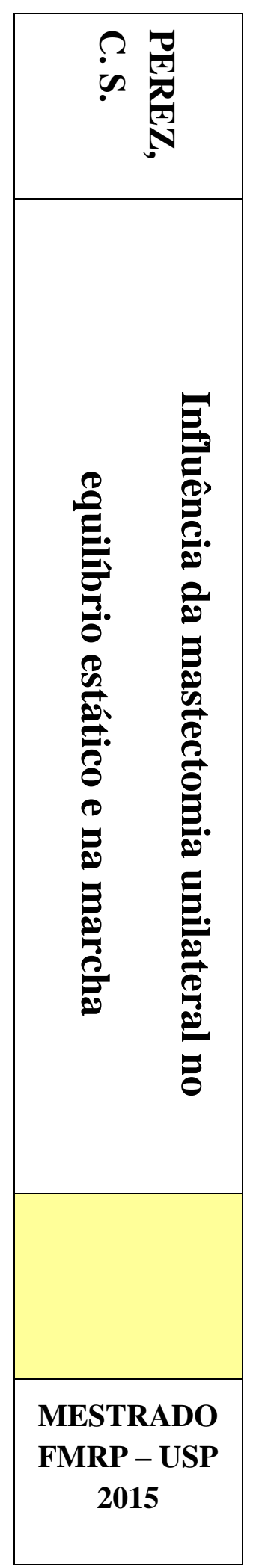


AUTORIZO A REPRODUÇÃO E DIVULGAÇÃO TOTAL OU PARCIAL DESTE TRABALHO, POR QUALQUER MEIO CONVENCIONAL OU ELETRÔNICO, PARA FINS DE ESTUDO E PESQUISA, DESDE QUE CITADA A FONTE.

Catalogação da Publicação

Serviço de Documentação da Faculdade de Medicina

Faculdade de Medicina de Ribeirão Preto da Universidade de São Paulo

Perez, Carla Silva

Influência da mastectomia unilateral no equilíbrio estático e na marcha. Ribeirão Preto 2015.

91 f.: il. ; $30 \mathrm{c}$

Orientadora: Guirro, Elaine Caldeira de Oliveira.

Dissertação (Mestrado) - Programa de Pós Graduação em Reabilitação e Desempenho Funcional. Universidade de São Paulo, Faculdade de Medicina de Ribeirão Preto - USP.

1. Neoplasias da mama. 2 Matectomia. 3. Marcha. 4. Equilíbrio 
Nome: Carla Silva Perez

Título: Influência da mastectomia unilateral no equilíbrio estático e na marcha

Dissertação apresentada ao Programa de PósGraduação em Reabilitação e Desempenho Funcional - FMRP/USP para obtenção do Título de Mestre em Ciências.

Área de Concentração: Fisioterapia

Aprovado em:

Banca Examinadora

Prof. Dr. Instituição:

Julgamento: Assinatura:

Prof. Dr. Instituição:

Julgamento: Assinatura:

Prof. Dr. Instituição: Assinatura: 


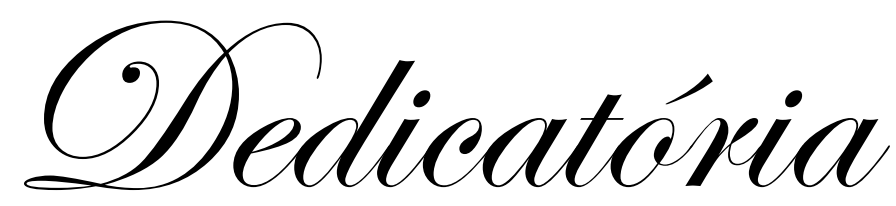


Dedico este trabalho aos meus pais, Marcelo e Marta e à minha irmã Bruna 
Agradecimentos 
Primeiramente à minha orientadora, Profa. Dra. Elaine Caldeira de Oliveira Guirro, pela confiança e oportunidade a mim concedida e por tornar possível a realização deste trabalho, concretizado através de seu conhecimento, sua orientação e sua dedicação.

Ao Prof. Dr. Paulo Roberto Pereira Santiago, pelo exemplo de profissional e pessoa, pela ajuda e imensurável contribuição na realização deste trabalho.

Ao Programa de Pós-Graduação em Reabilitação e Desempenho Funcional da Universidade de São Paulo da Faculdade de Medicina de Ribeirão Preto, através do qual tive a oportunidade de dar um passo importante e valioso rumo ao crescimento científico e profissional.

Às minhas amigas do LAIDEF (Vânia, Laís, Gabriela, Monique, Adriana), que sempre muito companheiras me proporcionaram bons momentos e tornaram tudo muito mais fácil e divertido durante esses anos.

Ás minhas amigas Thaís e Maita, que foram minhas companheiras do início de trabalho e para vida.

Aos amigos do LARF (Hugo, Ariane,Natanael) pelo apoio, incentivo e solidariedade prestada, se fazendo sempre uma divertida companhia. Almir, pela disponibilidade, principalmente na orientação dá análise estatística.

Às amigas do LaBioCoM (Luciana, Nathália) e especialmente a Priscila pela sua paciência em me ensinar e a companhia sempre agradável.

Aos voluntários, enfermeiras e toda equipe do REMA a Antonieta, pelos preciosos ensinamentos a mim passados.

Com muita gratidão, às mulheres acometidas pelo Câncer de Mama, que foram capazes de enxergar a grandeza de sua colaboração neste projeto.

Aos meus antigos amigos, que compreenderam minha ausência e se fizeram presentes mesmo quando distantes, com sua amizade, carinho e me apoiando nesta jornada.

Ao meu companheiro e querido namorado, Thales, pela compreensão, paciência e amor em todos os momentos, sendo ainda mais evidente nessa etapa tão importante.

Aos meus pais, por me proporcionarem essa oportunidade, pelo apoio incondicional e imensurável, estando sempre ao meu lado servindo como verdadeiros pilares em minha vida, me orientando e amparando em todos os momentos desta trajetória.

Aos meus avós, que mesmo em sua simplicidade souberam entender a importância desta realização para mim.

E agradeço a Deus, por me ajudar sempre e por poder citar estas pessoas neste momento tão importante. Obrigada por colocá-las em minha vida. 
A todos aqueles que de alguma forma contribuíram para a realização deste trabalho.

O meu, Muito Obrigada! 
"Alarefa não étanto ver aquilo que ninguém viu, mas pensaro que ninguém ainda pensou sobre aquilo que todo mundo vê." (Ohthur Ochopenhauer) 


\section{RESUMO}

\section{PEREZ, C. S. Influência da mastectomia unilateral no equilíbrio estático e na marcha.}

2015. 91 f. Dissertação (Mestrado) - Faculdade de Medicina de Ribeirão Preto, Universidade de São Paulo, Ribeirão Preto, 2015

Mulheres submetidas à mastectomia, apresentam assimetrias posturais, assim como alterações na cinemática do movimento do ombro e tronco. O objetivo deste estudo foi avaliar o equilíbrio estático bem como a marcha em mulheres submetidas à cirurgia de mastectomia unilateral. Para tanto, foram analisadas 42 mulheres, divididas em dois grupos: mulheres submetidas à mastectomia unilateral (GM), com idade média de 53,77士7,24 anos, e mulheres

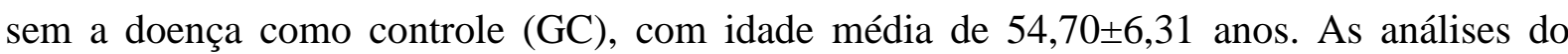
equilíbrio estático e da marcha foram efetuadas com sistema Vicon System (VICON-MXT40S, Oxford, Inglaterra). Foi avaliado o equilíbrio estático com olhos abertos e olhos fechados, com e sem o uso da prótese mamária externa, por meio da área e do deslocamento do centro de massa projetado no chão, assim como o ângulo da coluna. Na marcha, foram avaliados os parâmetros espaço-temporal com e sem o uso da prótese mamária externa, e a oscilação dos membros superiores e do tronco. Foi aplicado o teste de normalidade de Shapiro-Wilk, diante de uma distribuição normal e relacionada, aplicou-se o teste $\mathrm{T}$ relacionado, e para amostras independentes, teste $\mathrm{T}$ independente, em distribuição não paramétrica, foi aplicado Wilcoxon para variáveis relacionadas e Mann-Whitney, para variáveis independentes. Foi fixado o nível crítico de $5 \%(\mathrm{p}<0,05)$, o processamento dos dados efetuado pelo software SPSS, versão 17.0. A análise do equilíbrio estático apontou aumento significativo na área e no deslocamento do centro de massa projetado no chão, e deslocamento médio-lateral do ângulo da coluna. Na marcha, houve piora dos parâmetros espaço-temporal e menor oscilção do membro superior homolateral à cirurgia para movimentos de flexão/extensão e abdução/adução, o tronco apresentou menor oscilação médio-lateral. A prótese parece não ter influenciado no equilíbrio e na marcha. Os resultados sugerem que a mastectomia unilateral pode afetar o equilíbrio e a marcha.

Palavras-chave: neoplasias da mama, mastectomia, marcha, equilíbrio postural. 


\begin{abstract}
CARLA SILVA PEREZ. Influence of mastectomy unilateral in static balance and gait. 2015. 91 f. Master Thesis - Faculty of Medicine of Ribeirão Preto, University of São Paulo, Ribeirão Preto, 2015.

Women undergoing mastectomy, have postural asymmetries as well as changes in the kinematics of the movement of the shoulder and spine. The objective of this study was to evaluate static balance and gait in women undergoing unilateral mastectomy surgery. Therefore, 42 women were analyzed, divided into two groups: women who underwent unilateral mastectomy (GM) with a mean age of $53.77 \pm 7.24$ years, and women without the disease as control (GC) with a mean age of $54.70 \pm 6.31$ years. Analyses of static equilibrium and gait was performed with Vicon System (MX-T40S-VICON, Oxford, England). We evaluated the static balance with eyes open and eyes closed, with and without the use of external breast prosthesis through the area and the center of mass displacement designed on the floor, as well as the angle of the spine. On the gait were evaluated spatiotemporal parameters with and without the use of external breast prosthesis and the oscillation of the upper limbs and trunk during walking. The functionality of the upper limbs was measured by the DASH questionnaire, and the level of physical activity by IPAQ. We used the ShapiroWilk normality test, before a normal and related distribution, we applied the related test for independent samples and, independent $\mathrm{t}$ test, in non-parametric distribution, Wilcoxon was applied to related variables and Mann Whitney test for independent variables was set the critical level of 5\% ( $\mathrm{p}<0.05)$, the processing of data carried out by SPSS software, version 17.0. The static equilibrium analysis indicated a significant increase in the area and the center of mass offset projected on the ground and the medial-lateral displacement of the spine angle. On the march, there was worsening of spatiotemporal parameters and lower swing in arm ipsilateral to surgery for flexion/extension and abduction/adduction, trunk shows less mediallateral oscillation. The prosthesis seems to have no influence on balance and gait. The results suggest that unilateral mastectomy can affect the balance and gait.
\end{abstract}

Key-words: breast cancer, mastectomy, balance, gait, arm swing 


\section{LISTA DE FIGURAS}

Figura 1. Ciclo da marcha normal, ilustrando os eventos da marcha. Fase de apoio: CI (contato inicial), RC (resposta a carga), AM (apoio médio), AT/PB (apoio terminal/pré balanço). Fase de balanço: BI (balanço inicial), BM (balanço médio), $\mathrm{BF}$ (balanço final)

Figura 2. Fluxograma de distribuição dos grupos de mulheres mastectomizadas (GM) e grupo controle (GC)

Figura 3. Imagem ilustrativa dos pontos utilizados para realização da medição da perimetria

Figura 4. Imagem ilustrativa da avaliação do tamanho das mamas. Onde x é a distância do mamilo a margem esternal lateral e y é a distância do mamilo ao sulco inframamário

Figura 5. Foto ilustrativa da pesagem das próteses mamárias externas 20

Figura 6. Imagem ilustrativa do pocisionamento dos marcadores do protocolo Plug-ingait full body (VICON)

Figura 7. Foto ilustrativa da avaliação do equilíbrio estático com o sistema VICON......22

Figura 8. Área da elipse do deslocamento do centro de massa projetado no chão, com 95\% de confiança. Onde A: deslocamento anteroposterior, B: deslocamento médio-lateral.

Figura 9. Foto ilustrativa da avaliação da marcha captada pelo sistema VICON 24 
Figura 10. Oscilação do ombro no plano sagital durante o ciclo da marcha. A: Oscilação do ombro direito versus ombro esquerdo do grupo controle (GC). B: Oscilação do ombro homolateral à cirurgia versus ombro contralateral à cirurgia do grupo de mastectomizadas (GMCP). C: Oscilação do ombro esquerdo do grupo controle (GC) e ombro homolateral a cirurgia do grupo de mastectomizadas (GMCP). Apresentado em mediana (primeiro quartil, terceiro quartil). Abreviação, TC: toque de calcanhar.

Figura 11. Oscilação do ombro no plano coronal durante o ciclo da marcha. A: Oscilação do ombro direito versus ombro esquerdo do grupo controle (GC). B: Oscilação do ombro homolateral à cirurgia versus ombro contralateral à cirurgia do grupo de mastectomizadas (GMCP). C: Oscilação do ombro esquerdo do grupo controle (GC) e ombro homolateral a cirurgia do grupo de mastectomizadas (GMCP). Apresentado em mediana (primeiro quartil, terceiro quartil). Abreviação, TC: toque de calcanhar.

Figura 12. Oscilação do ombro no plano transversal durante o ciclo da marcha. A: Oscilação do ombro direito versus ombro esquerdo do grupo controle (GC). B: Oscilação do ombro homolateral à cirurgia versus ombro contralateral à cirurgia do grupo de mastectomizadas (GMCP). C: Oscilação do ombro esquerdo do grupo controle (GC) e ombro homolateral a cirurgia do grupo de mastectomizadas (GMCP). Apresentado em mediana (primeiro quartil, terceiro quartil). Abreviação, TC: toque de calcanhar.

Figura 13. Oscilação do ângulo da coluna no plano sagital durante o ciclo da marcha. A: Oscilação da coluna anteroposterior do grupo controle (GC). B: Oscilação anteroposterior do grupo de mastectomizadas (GMCP). C: Oscilação anteroposterior do grupo controle (GC) versus grupo de mastectomizadas (GMCP). Apresentado em mediana (primeiro quartil, terceiro quartil). Abreviação, TC: toque de calcanhar. 36 
Figura 14. Oscilação do ângulo da coluna no plano frontal durante o ciclo da marcha. A: Oscilação da coluna médio-lateral do grupo controle (GC). B: Oscilação médio-lateral do grupo de mastectomizadas (GMCP). C: Oscilação médiolateral do ângulo da coluna do grupo controle (GC) versus grupo de mastectomizadas (GMCP). Apresentado em mediana (primeiro quartil, terceiro quartil). Abreviação, TC: toque de calcanhar. 


\section{LISTA DE TABELAS}

Tabela 1. Características gerais das voluntárias dos grupos experimentais: grupo de mastectomizadas (GM) e grupo controle (GC) 15

Tabela 2. Características relacionadas ao tratamento do câncer de mama, das voluntárias do grupo experimental: GM (grupo de mulheres mastectomizadas). 16

Tabela 3. Comparação do nível de atividade física e funcionalidade dos membros superiores das voluntárias dos grupos experimentais: grupo de mastectomizadas (GM) e grupo controle (GC). 17

Tabela 4. Valores referente a área da elipse formado pelo centro de massa projetado no chão em centímetros, do grupo de mulheres mastectomizadas com o uso da prótese mamária externa $(\mathrm{GMCP})$, sem o uso da prótese mamária externa (GMSP) e grupo controle (GC), com olhos abertos (AO) e olhos fechados (OF)

Tabela 5. Valores referentes ao deslocamento médio-lateral (X) e anteroposterior (Y), encontrados dentro da área da elipse do centro de massa projetado no chão em centímetros, do grupo de mulheres mastectomizadas com o uso da prótese mamária externa (GMCP), sem o uso da prótese mamária externa (GMSP) e grupo controle (GC), com olhos abertos (AO) e olhos fechados (OF)

Tabela 6. Valores referentes ao ângulo da coluna anteroposterior (X) e médio-lateral (Y), do grupo de mulheres mastectomizadas com o uso da prótese mamária externa (GMCP), sem o uso da prótese mamária externa (GMSP) e grupo controle $(\mathrm{GC})$

Tabela 7. Valores referentes aos parâmetros espaço temporais da marcha do grupo de mulheres mastectomizadas com o uso da prótese mamária externa (GMCP), sem o uso da prótese mamária externa (GMSP) e grupo controle (GC). 29 
Tabela 8. Diferença ente o ângulo máximo e mínimo do ombro durante a marcha, para os movimentos flexão/extensão (F/E), abdução/adução (A/A) e rotação interna/rotação externa (RI/RE), do grupo de mulheres mastectomizadas com o uso da prótese mamária externa (GMCP), sem o uso da prótese mamária externa (GMSP), lado homolateral à cirurgia (CI) e contralateral à cirurgia (CL) e grupo controle (GC) lado direito (D) e lado esquerdo (E) 30 


\section{SUMÁRIO}

Resumo

Abstract

Lista de Figuras

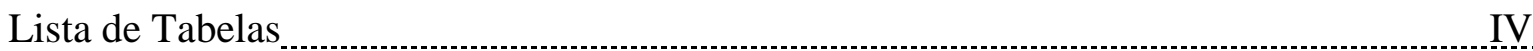

1. INTRODUÇÃO

2. REVISÃO DE LITERATURA

2.1 Câncer de mama

2.2 Tratamentos para o câncer de mama

2.3 Morbidades após tratamento para o câncer de mama

2.4 Diminuições da capacidade funcional após tratamento do câncer de mama _..................

$2.5 \mathrm{O}$ controle postural e a marcha 8

3. OBJETIVOS 11

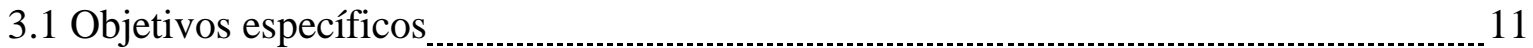

3.2 Objetivo Secundário $\ldots \ldots \ldots$

4. MATERIAL E MÉTODOS

4.1 Tipo de pesquisa e delineamento do estudo

4.2 Amostra

4.3 Critérios de Inclusão

4.4 Critérios de Exclusão

4.5 Aspectos Éticos

4.6 Espaços Físicos

4.7 Procedimento Experimental 
6.1 Resultados referentes à avaliação do equilíbrio estático 26

6.2 Resultados referentes à avaliação da marcha 28

7. DISCUSSÃO 39

8. CONCLUSÃO 45

REFERÊNCIAS

ANEXOS 57

APÊNDICE 66 


\section{- Fotradusãa}




\section{INTRODUÇÃO}

O câncer de mama é o mais frequente na população feminina, representando $22 \%$ dos casos de câncer a cada ano. Apesar da mastectomia representar um procedimento altamente mutilante para grande parte das mulheres, significa tratamento curativo em 98\% dos casos (INCA, 2004, 2012).

Várias morbidades funcionais afetam a mulher após o tratamento cirúrgico de mastectomia, como o linfedema, dor em região cervical e de ombro, distúrbios sensoriais, alteração na cinemática de membros superiores e tronco, e alterações posturais. A maioria destas morbidades afetam o membro superior homolateral à cirurgia. (Bossombra et al., 2002; Kurman et al., 2003; Rezende et al., 2005; Gouveia, et al., 2008).

A assimetria de partes moles e a alteração na distribuição de massa na parede torácica, consequência da retirada de uma das mamas, acarreta uma série de alterações posturais (Cheville et al., 2007). Existindo alteração de um segmento corporal ou da postura, consequentemente haverá um deslocamento do centro de gravidade e provável instabilidade dinâmica (Danis et al., 1998).

Sabe-se que o tamanho das mamas repercute na alteração do centro de gravidade normal e também nas curvaturas fisiológicas da coluna (Araújo et al., 2007; Fernandes et al., 2007). Alterações exterioceptivas e proprioceptivas das estruturas musculares poderão promover um ajuste postural compensatório (Melo et al., 2010).

Assimetrias posturais foram observadas em mulheres com mastectomia unilateral, como maior ângulo de inclinação do tronco para o lado homolateral à cirurgia, posicionamento mais elevado da escápula do lado operado, maior ângulo de rotação da pelve, maior inclinação do tronco para frente e escápulas abduzidas (Rostkowska, et al., 2006; Gouveia, Gonzales et al., 2008).

O desarranjo postural é decisivo na alteração do equilíbrio, e este na marcha (Dye et al., 2013). Mulheres após o tratamento para o câncer de mama apresentam uma redução na capacidade de controle postural (Wampler et al., 2007).

$\mathrm{O}$ interesse pelo estudo das funções de tronco e membros superiores durante a marcha é recente, e a quantificação desses segmentos ainda é limitada (Kubo et al., 2006). Ao se observar o padrão de marcha de mulheres submetidas à mastectomia é importante também avaliar todos os elementos complicadores do movimento das articulações do tronco superior decorrentes desta cirurgia. 
Após a cirurgia de mastectomia, alterações cinemáticas do membro superior nos planos sagital, coronal, escapular e também na coluna são encontradas mesmo após anos do tratamento (Shamley et al., 2009; Crosbie et al., 2010). Estas alterações comprometem principalmente os movimentos de flexão e abdução do ombro, juntamente com a diminuição da força de alguns grupos musculares responsáveis por estes movimentos, e pela estabilização da cintura escapular (Gouveia, Gonzales 2008).

O decréscimo na ativação muscular adjacente ao ombro e na cintura escapular são morbidades também decorrentes do procedimento cirúrgico de matsectomia (Shamley et al., 2006, 2012). Quando aliada a linfadenectomia, observa-se um acréscimo da atividade do músculo trapézio superior, possivelmente de forma compensatória para estabilização escapular (Pereira et al., 2009).

Alterações presentes em qualquer movimento de uma articulação poderão afetar a marcha globalmente, visto que o corpo humano é um sistema articulado (Kavanagh et al., 2003).

Diante do exposto, justifica-se a importância de uma análise sistematizada e quantificada do equilíbrio e da marcha de mulheres mastectomizadas, permitindo assim, a correta compreensão e conhecimento das alterações funcionais do aparelho locomotor decorrentes da cirurgia, a fim de aperfeiçoar as formas de intervenção fisioterapêutica frente às mudanças adaptativas e suas consequências.

Configura-se assim, a hipótese de que ocorram alterações estáticas e dinâmicas decorrentes da mastectomia unilateral para tratamento do câncer de mama. 
Crevisãa de Siteratura 


\section{REVISÃO DE LITERATURA}

\subsection{Câncer de mama}

A incidência do câncer vem aumentando nos países em desenvolvimento econômico, como resultado do contínuo crescimento e envelhecimento da população mundial, juntamente com a adição de estilos de vida associados ao surgimento da doença, entre eles, o tabagismo, inatividade física e a má alimentação, agravando o ônus global decorrentes desta doença (Jemal et al., 2011).

O câncer é a principal causa de morte em países desenvolvidos, e a segunda em países em desenvolvimento. O câncer de mama é o segundo tipo mais frequente no mundo em diagnóstico, e o mais frequente na população feminina, sendo a principal causa de morte por câncer entre as mulheres, responsável por $23 \%$ do total dos casos de câncer, e 14\% das mortes por câncer, responde pelo aumento do número de mortes por câncer em mulheres economicamente ativa, mudança ocorrida na última década (Ferlay et al., 2010, Jemal et al., 2011; Brasil/INCA, 2013).

No Brasil, são descobertos milhares de casos de Cãncer de mama a cada ano, sendo que a taxa de mortalidade ainda continua elevada, muito provavelmente porque a doença seja diagnosticada em estágios mais avançados. Sendo o tipo mais frequente nas regiões Sul, Sudeste, Centro-Oeste e Nordeste (INCA, 2013).

\subsection{Tratamento do câncer de mama}

A modalidade terapêutica mais utilizada para o tratamento do câncer de mama é a abordagem cirúrgica, podendo esta ser conservadora ou não conservadora, sendo a remoção total da mama denominada mastectomia. Fatores como o estadiamento inicial do tumor, tipo histopatológico, tamanho e a idade da paciente, determinarão a opção mais adequada dentre as várias técnicas cirúrgicas de escolha para o tratamento (INCA, 2004).

O tratamento cirúrgico do câncer de mama empregado atualmente baseia-se em uma série de técnicas que sofreram significativas mudanças desde os relatos de William Stewart Hasted e Willy Mayer, publicados em 1894 (Haagensen, 1946).

Mesmo tendo em vista os diversos avanços em relação ao tratamento oncológico, a cirurgia mostra-se ainda o principal recurso para o controle locoregional 
da doença, prevenindo desta forma sua disseminação. Atualmente preconiza-se cirurgias conservadoras, além da possibilidade de avaliação do prognóstico da doença através da obtenção do controle locoregional, orientação da terapêutica complementar utilizando como indicadores o diagnóstico do linfonodo sentinela e o exame anatomopatológico do extrato extirpado (Rietman et al.,2002; Lyman et al., 2005).

A primeira abordagem cirúrgica para tratamento do câncer de mama foi a mastectomia radical, descrita por Willian Halsted em 1894, e consistia na remoção completa da mama, além do músculo peitoral maior e menor, bem como linfadenectomia total. Considerada como padrão de tratamento por quase 100 anos (Sakarafas, Safioleas, 2010, Halsted et al., 2014), entretanto ocasionava morbidades (Samphao et al., 2008).

Surgiram variações da mastectomia radical, denominadas de mastectomia radical modificada tipo Patey, onde é removida a glândula mamária, o músculo peitoral menor, além da linfadenectomia axilar, com preservação do músculo peitoral maior (Patey,1967). Madden, na qual há a extirpação da glândula mamária e linfadenetomia axilar, mas com preservação dos músculos peitoral menor e maior (Madden; Kandalaft; Bourque, 1972).

Veronesi et al, (2002) acompanharam de forma randomizada pacientes com tumores pequenos submetidas a cirurgia conservadora e mastectomia radical com follow-up de 20 anos, e concluiu que não há diferença significativa na sobrevida, sendo portanto mais interessante a cirurgia conservadora para estas pacientes.

Apesar da remoção cirúrgica do tumor, na maioria das vezes, é necessário associar tratamentos adjuvantes locais e sistêmicos, sendo os principais e com maior frequência a radioterapia, quimioterapia e hormonioterapia (Kaufman et al., 2007).

A radioterapia é um tratamento local, que utiliza radiação ionizante, produzida por equipamentos ou emitida por radioisótopos naturais, tendo como objetivo a interrupção do crescimento e da reprodução celular. Como as células tumorais reproduzem-se mais rapidamente, estas são mais suscetíveis; sendo efetiva na prevenção de recorrência locoregional, tanto em cirurgias conservadoras como nas mastectomias (Hojris et al., 2000).

Através de fármacos antineoplásicos, a quimioterapia tem como objetivo destruir células neoplásicas, com uma atuação sistêmica e loco regional, agredindo e destruindo células por todo corpo (Ladeira, 1997), os principais objetivos da quimioterapia são: 
reduzir a mortalidade com toxicidade reduzida; melhorar as opções cirúrgicas (Kaufman et al.,2006).

Ainda como tratamento adjuvante ao câncer de mama, utiliza-se a hormonioterapia, porém sua indicação é apenas às mulheres que apresentam receptores hormonais positivos (Buckley et al., 1989).

\subsection{Morbidades após tratamento para o câncer de mama}

Muitos dos pacientes com câncer sofrem de efeitos a curto e longo prazo, induzidos pelos mecanismos patológicos da doença (Pautex et al., 2008), da terapia utilizada, o tipo cirúrgico (Lauridsen et al.,2005), além da influência dos demais tratamentos adjuvantes para o controle locoregional e sistêmico da doença. O tratamento quimioterápico já é descrito na literatura como preditor para um aumento do risco de quedas em indivíduos após tratamento da doença (Filler et al., 2011).

A cirurgia continua sendo um dos pilares para o tratamento do câncer de mama, e, diferentes propostas de técnica cirúrgica, reduziram a lesão nos tecidos, porém a dor e o comprometimento funcional continuam ocorrendo (Cheville et al., 2007), favorecendo inclusive a presença da síndrome miofascial, com presença de pontos gatilhos na musculatura de pescoço e ombros (Fernandes Lao et al., 2012).

Mulheres submetidas à mastectomia apresentam pior qualidade de vida quando comparadas a mulheres que realizaram cirurgias conservadores, e este quadro é agravado quando são submetidas à terapia sistêmica, como a quimioterapia (Makluf et al., 2005).

A distribuição de massa no tronco pode influenciar a postura, sendo assim, o tamanho das mamas pode alterar o arranjo postural (Lapid et al., 2013), e interferir na capacidade funcional de mulheres (Araujo, 2007).

A mutilação sofrida com a mastectomia promove assimetria de partes moles, alteração na mobilidade e na distribuição de massa através da parede torácica (Cheville et al. 2007).

Em mulheres mastectomizadas, essa diferença de distribuição de massa muda em comparação com o hemicorpo contralateral à cirurgia, alterando assim sua postura (Rostmaska, Bak, 2006), tanto que, em mulheres submetidas a reconstrução imediata da mama, a postura parece não ter sido afetada (Ciesla et. al.,2010). 
A extirpação de uma das mamas pode ocasionar um quadro de alterações posturais, sendo encontrados na literatura, um maior ângulo de inclinação do tronco, posicionamento mais elevado da escápula do lado operado, maior ângulo de torção da pelve, maior inclinação do tronco para frente e escápulas mais abduzidas (Rostkowska, Bak et al.2006; Gouveia, Gonzales et al., 2008).

O prejuízo da função do ombro e tronco é há tempos conhecido e frequentemente visto como sequela do tratamento para o câncer de mama (Aitken, 1983; Lauridessen et al., 2005,).

Para uma movimentação normal e eficiente do membro superior, é necessária mobilidade das articulações glenoumeral, escapulotorácica, acromioclavicular e esternoclavicular funcionantes e livres de dor. Quando o movimento em alguma destas articulações é desproporcional, existe a possibilidade de dor e trauma em longo prazo (Kapandji, 2000).

Mesmo em pacientes com cirurgia tardia, há relato de dor, diminuição da força e da função do braço afetado, os movimentos de flexão e abdução do ombro, tanto passiva quanto a ativa, mostram-se os mais prejudicados, quando comparados ao membro superior contralateral à cirurgia (Gouveia, Gonzales 2008). Foi observado um decréscimo da atividade EMG do músculo serrátil anterior no período entre o pré e o pós-operatório de três meses, já o músculo trapézio superior mostrou um acréscimo de sua atividade durante o período pós-operatório, possivelmente de forma compensatória para estabilização escapular (Pereira et. al. 2009).

$\mathrm{Na}$ mastectomia radical, com a retirada do peitoral menor não será possível rodar a escápula inferiormente, já, a retirada do peitoral maior, trará a maior perda funcional, pois prejudicarão os movimentos de flexão horizontal, adução e a rotação interna, causando uma tendência de hipertrofia no músculo trapézio superior homolateral a cirurgia, por uma ação compensatória nos movimentos de abdução e flexão do ombro (Hack, 2009).

\subsection{Diminuições da capacidade funcional após tratamento do câncer de mama}

Além da dor, piora da qualidade de vida, alterações posturais, alteração na cinemática de tronco e ombros, as mulheres com câncer de mama muitas vezes encontram limitações na força muscular, e na função de controle do equilíbrio neuromuscular, seja em função da mudança do seu centro de massa, ou ainda pela 
terapia adjuvante ao tratamento (Wampler et al.,2007; Rietman et al., 2002; Niederer et al., 2013).

Historicamente, médicos aconselhavam pacientes oncológicos a evitar atividades físicas. No entanto, com o aumento da sobrevida juntamente com o risco de novas recidivas, trouxeram novas formas de recomendação de atividade física, a pesquisa emergente em exercício, assim como as novas diretrizes contrapõem as antigas, recomendações, demonstrando eficácia e segurança ao treinamento físico durante e após a terapia do câncer (Schmitz et al., 2010; Sancho et al., 2015).

Os recentes resultados com relação ao estado funcional exigem uma maior exploração desta limitação em pacientes no tratamento do câncer, e sobreviventes da doença (van Abellan Kan et al., 2009). Particularmente no câncer de mama, muitas mulheres que foram submetidas à mastectomia relatam queixas de alterações posturais e também muitas vezes caminhavam de forma diferente, ou não utilizam o membro superior homolateral à cirurgia, poupando este durante suas atividades (Collins et al., 2004).

\subsection{O controle postural e a marcha}

O equilíbrio está intimamente ligado ao balanço postural, que por sua vez é determinado pelo trajeto do centro de massa. Dessa forma, alterações de postura e equilíbrio podem estar relacionadas com alterações do centro de massa (Mochizuki et al., 2003).

A condição conhecida por defender a estabilidade em situações estáticas é que a projeção vertical do centro de massa $(\mathrm{CM})$ deve situar-se dentro da base de apoio (BOS). A combinação de movimentos que se sucedem na marcha faz com que o centro de massa seja projetado na vertical e dentro da base de suporte (BDS), que tem o deslocamento relacionado com o aumento ou diminuição da BDS. Portanto, a alteração do diâmetro da mesma é determinada pelas alterações do CDM, sendo o controle postural promovido pela interação entre CDM e BDS (Hof et al., 2004; Maki et al., 1996).

A marcha tem como objetivo o deslocamento do indivíduo de maneira versátil e com o menor gasto energético possível, é dividida em duas fases, apoio e balanço (Figura 1). A fase de apoio da marcha ocorre quando o pé está em contato com o solo, e 
o tronco faz a ultrapassagem do membro apoiado. A fase de balanço ocorre quando o pé não está mais sustentado o peso e move-se para frente (Magee, 2005).

Tanto a fase de apoio quanto a fase de balanço podem ser subdivididas em períodos, demarcados por sucessivos eventos. A fase de apoio que compreende o contato inicial, seguida pela resposta à carga e apoio médio, e as fases de apoio terminal e pré-balanço, que consiste no período de transferência do peso. A fase de balanço inicia-se quando o pé não está mais sustentado o peso do corpo, primeiro com uma aceleração, correspondente ao balanço inicial e após uma desaceleração, correspondente ao balanço médio e terminal (Rose,1980).

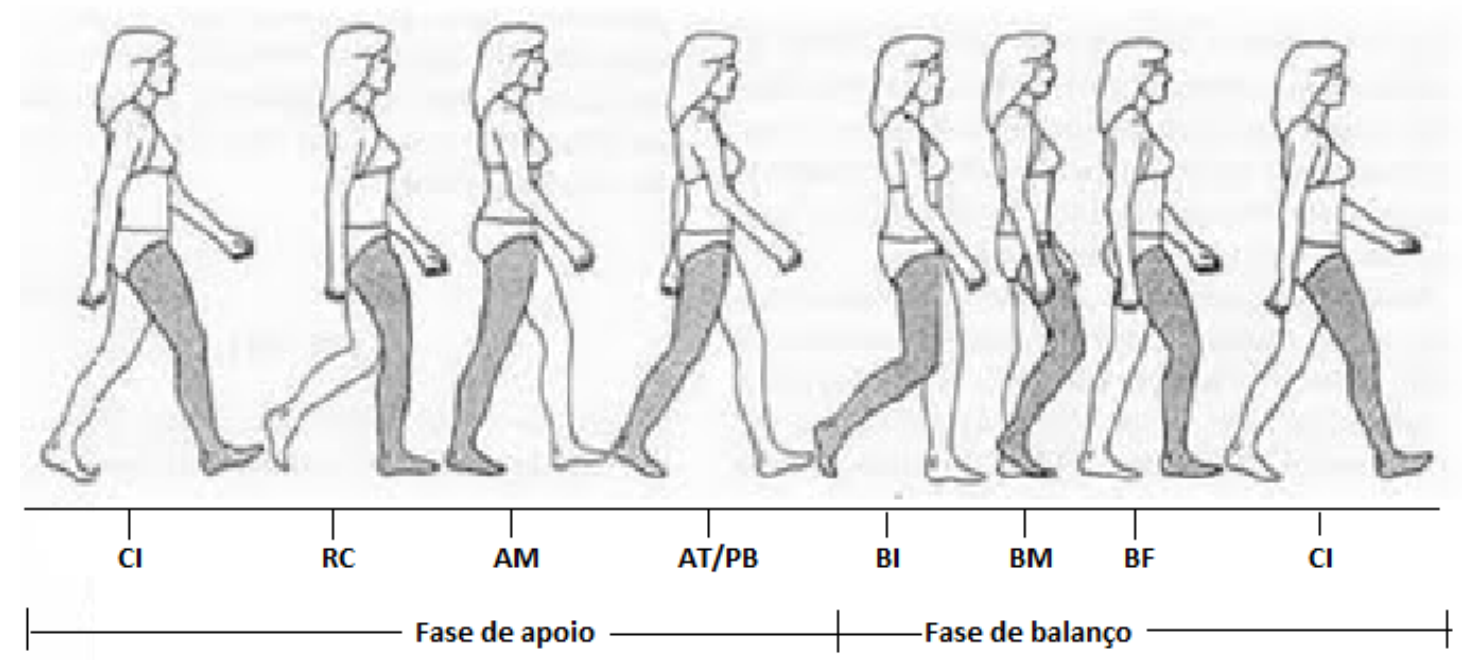

Figura 1. Ciclo da marcha normal, ilustrando os eventos da marcha. Fase de apoio: CI (contato inicial), RC (resposta a carga), AM (apoio médio), AT/PB (apoio terminal/pré balanço). Fase de balanço: BI (balanço inicial), BM (balanço médio), BF (balanço final). (Modificado de Rose J., Gamble JG. Marcha Humana. Rose J, Gamble JG. Marcha. São Paulo: Premier, 1993. p.25) 
Objetiva 


\section{OBJETIVO}

Avaliar a influência da mastectomia unilatearal no equilíbrio estático e na cinemática da marcha.

\subsection{Objetivos específicos}

- Avaliar a área da elipse formada pelo centro de massa projetado no chão na posição estática;

- Avaliar o deslocamento anteroposterior e médio-lateral do centro de massa e do ângulo da coluna;

- Avaliar os parâmetros espaço temporais da marcha;

- Avaliar a oscilação dos ombros no ciclo da marcha;

- Avaliar a oscilação da coluna no ciclo da marcha.

\subsection{Objetivos secundários}

Avaliar a influência da prótese externa no equilíbrio estático e nos parâmetros espaço temporais da marcha. 
Materiale

Metodos

12 


\section{MATERIAL E MÉTODOS}

\subsection{Tipo de pesquisa e delineamento do estudo}

Estudo observacional, prospectivo, controlado e transversal, aprovado pelo Comitê de Ética e Pesquisa em Seres Humanos da Faculdade de Medicina de Ribeirão Preto, processo HCRP n ${ }^{\circ} 8341 / 2013$.

\subsection{Amostra}

Foram convidadas e eleitas a participar deste estudo, 96 mulheres, sendo que 54 foram excluídas pelos critérios estabelecidos, ou não compareceram à avaliação. Foram incluídas 42 mulheres, determinado pelo cálculo amostral, divididas em dois grupos: GM: grupo de mulheres submetidas a mastectomia unilateral para o tratamento do câncer de mama e GC: grupo de mulheres sem a doença (Figura 2). Os grupos foram pareados com relação à idade, altura e massa corporal das voluntárias.

As mulheres mastectomizadas foram convidadas enquanto estavam em acompanhamento no Núcleo de Ensino, Pesquisa e Assistência na Reabilitação de Mulheres Mastectomizadas (REMA), da Escola de Enfermagem de Ribeirão Preto da Universidade de São Paulo (EERP-USP).

As voluntárias de ambos os grupos foram submetidas a avaliação do equilíbrio estático e da marcha, realizada no Laboratório de Biomecânica e Controle Motor (LaBioCom) da Escola de Educação Física e Esporte de Ribeirão Preto, Universidade de São Paulo (EEFERP-USP).

\subsection{Critérios de Inclusão}

Foram incluídas no grupo de mulheres mastectomizadas (GM) mulheres com idade entre 35 e 65 anos, com índice de massa corpóreo (IMC), variando entre 18,5 e $39,9 \mathrm{Kg} / \mathrm{m}^{2}$ de superfície, submetidas a mastectomia unilateral. Para o grupo controle (GC) foram considerados os mesmos critérios de inclusão, exceto o critério relacionado à cirurgia. 


\subsection{Critérios de Exclusão}

Foram excluídas do grupo de voluntárias mastectomizadas (GM) mulheres com mais de dois anos de cirurgia, segundo critérios de Ciesla e Polom (2010), com diagnóstico de doenças de ordem reumáto-ortopédicas que pudessem interferir com a função dos membros superiores e inferiores; com queixas de equilíbrio; alteração cognitiva, que apresentassem linfedema; com lesão do sistema nervoso periférico de membros superiores permanentes (neurotmese); mulheres submetidas a reconstrução mamaria, com uso de prótese mamária interna ou expansor na região mamária; mulheres com mamas pequenas, segundo critérios estabelecidos por Sachinni et al. (1991). Para o grupo de voluntárias controle (GC), foram considerados os mesmos critérios de exclusão, exceto os relacionados à cirurgia.

\begin{tabular}{|c|c|}
\hline \multicolumn{2}{|c|}{ Avaliadas para elegibilidade $(n=96)$} \\
\hline \multicolumn{2}{|c|}{$\downarrow$} \\
\hline \multicolumn{2}{|c|}{ Excluídas $(\mathrm{n}=54)$} \\
\hline \multicolumn{2}{|c|}{$\begin{array}{l}\text { Não atenderam aos critérios de inclusão }(n=38) \\
\text { Outros motivos }(n=16)\end{array}$} \\
\hline \multicolumn{2}{|c|}{$\downarrow$} \\
\hline \multicolumn{2}{|c|}{ Incluídas $(\mathrm{n}=42)$} \\
\hline$\downarrow$ & $\downarrow$ \\
\hline $\begin{array}{l}\text { Grupo de Mastectomizadas (GM) } \\
\qquad(\mathrm{n}=22)\end{array}$ & $\begin{array}{l}\text { Grupo de Controle (GC) } \\
\qquad(\mathrm{n}=20)\end{array}$ \\
\hline $\begin{array}{l}\text { - Avaliação do equilíbrio estático, com e } \\
\text { sem prótese externa; } \\
\text { - Avaliação da marcha, com e sem } \\
\text { prótese externa. }\end{array}$ & $\begin{array}{l}\text { - Avaliação do equilíbrio estático; } \\
\text { - Avaliação da marcha. }\end{array}$ \\
\hline
\end{tabular}

Figura 2. Fluxograma de distribuição dos grupos de mulheres mastectomizadas (GM) e grupo controle (GC).

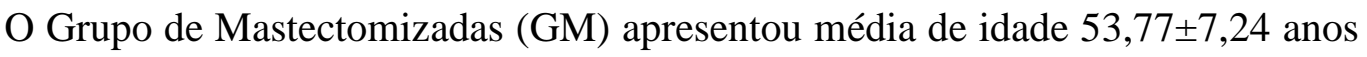
e IMC médio de 30,24 $\pm 5,83 \mathrm{Kg} / \mathrm{m}^{2}$, e o Grupo Controle (GC) apresentou média de

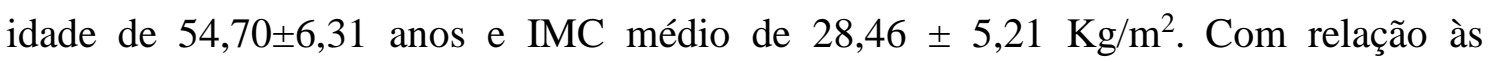
características gerais das voluntárias participantes do estudo, não houve diferenças significativas em relação aos grupos na linha de base, Tabela 1. 
Tabela 1 - Características gerais das voluntárias dos grupos experimentais: grupo de mastectomizadas (GM) e grupo controle (GC).

\begin{tabular}{lccc}
\hline Variáveis & GM & GC & $\boldsymbol{p}$ valor \\
\hline $\mathbf{N}$ & 22 & 20 & \\
Idade (anos) & $53.77(7.24)$ & $54.70(6.31)$ & 0,662 \\
Peso $(\mathbf{K g})$ & $75.85(14.14)$ & $73.80(15.51)$ & 0,656 \\
Altura (m) & $1.58(0.03)$ & $1.60(0.03)$ & 0,137 \\
IMC $\left(\mathbf{K g} / \mathbf{m}^{\mathbf{2}}\right)$ & $30.74(5.83)$ & $28.46(5.21)$ & 0,237 \\
Índice de Sachinni & $10 \mathrm{M}, 12 \mathrm{G}$ & $9 \mathrm{M}, 11 \mathrm{G}$ & \\
\hline
\end{tabular}

Valores apresentados em média (desvio-padrão). M: tamanho médio da mama, G: tamanha grande da mama. Sem diferença significativa nas comparações entre os grupos ( $p>0,05$, teste $t$ para amostras independentes), com relação a idade, peso, altura e IMC. $\mathrm{N}$ : número da amostra.

As características das voluntárias do grupo de mulheres mastectomizadas (GM), relativas ao tratamento cirúrgico e ao tratamento complementar do câncer de mama, estão apontadas na Tabela 2. 
Tabela 2 - Características relacionadas ao tratamento do câncer de mama, das voluntárias do grupo experimental: GM (grupo de mulheres mastectomizadas).

\begin{tabular}{lll}
\hline Tempo de cirurgia & $\leq 12$ meses & $\mathrm{n}=18$ \\
& $>12$ meses & $\mathrm{n}=4$ \\
& & \\
Lado cirurgia & Direito & $\mathrm{n}=8$ \\
& Esquerdo & $\mathrm{n}=14$
\end{tabular}

Linfadenectomia axilar, sim/não $\quad 21 / 1$

Prótese Externa

Peso (g): média (dp)

$367.68(191.21)$

Uso prévio, sim/não

Quimioterapia, sim/não

$22 / 0$

Radioterapia, sim/não

$8 / 14$

Hormonioterapia, sim/não

$16 / 6$

dp: desvio-padrão; n: número da amostra

Para mensurar o nível de atividade física das voluntárias foi aplicado a forma curta do International Physical Activity Questionnaire (IPAQ), versão 8 (IPAQ, 2011). O questionário contém perguntas relacionadas à frequência (dias por semana) e a duração (tempo por dia) da realização de atividades físicas moderadas, vigorosas e da caminhada, não apresentando diferença entre grupos, Tabela 3.

A funcionalidade dos membros superiores foi avaliada pela aplicação do Disabilities of the Arm, Shoulder, and Hand Questionnaire (DASH), este questionário foca na função dos membros superiores sob a perspectiva da voluntária (Orfalle et al., 2005), sendo que demonstrou deficiência significativa da funcionalidade de membros superiores no GM em relação ao GC (Tabela 3). 
Tabela 3 - Comparação do nível de atividade física e funcionalidade dos membros superiores das voluntárias dos grupos experimentais: grupo de mastectomizadas (GM) e grupo controle (GC).

\begin{tabular}{llccc}
\hline Variáveis & GM & GC & $\boldsymbol{p}$ valor \\
\hline DASHscore & & 21.66 & 1.60 & $<0.001$ \\
& & $(15.00,34.52)$ & $(0.20,3.94)$ & \\
IPAQ & Insuficientemente Ativo & $\mathbf{N}$ & $\mathbf{N}$ & \\
& Ativo & 9 & 8 & \\
& Muito Ativo & 3 & 8 & \\
& & & 4 &
\end{tabular}

Valores apresentados em mediana (P25, percentil 25 ou primeiro quartil; P75, percentil 75 ou terceiro quartil). Com diferença significativa nas comparações entre os grupos para funcionalidade dos membros superiores ( $\mathrm{p}<0,05$, Mann-Whitney); DASH: Disabilities of the Arm, Shoulder, and Hand questionnaire; IPAQ: International Physical Activity Questionnaire, N: Número da amostra.

\subsection{Aspectos Éticos}

Todas as voluntárias foram informadas previamente sobre o procedimento de avaliação a que seriam submetidas concordando em participar assinaram o Termo de Consentimento Livre e Esclarecido (APÊNDICE 1 e 2), formulado de acordo com a resolução 466/2012 o Conselho Nacional de Saúde (CNS).

Os itens do instrumento foram lidos para as voluntárias durante entrevista com os pesquisadores, sendo que todas as informações obtidas estão arquivadas na Faculdade de Medicina de Ribeirão Preto - USP/SP, sob a guarda do coordenador do projeto. 


\subsection{Espaços Físico}

Foram utilizados o Laboratório de Intervenção em Fisioterapia Dermatofuncional (LAIDEF) da Faculdade de Medicina de Ribeirão Preto Universidade de São Paulo (FMRP/USP), e o Laboratório de Biomecânica e Controle Motor (LaBioCoM) da Escola de Educação Física e Esportes de Ribeirão Preto (EEFERP-USP).

\subsection{Procedimento Experimental}

Todas as voluntárias foram submetidas à anamnese específica e mensuração da pressão arterial, no período matutino.

A avaliação da volumetria dos membros superiores, a fim de avaliar a presença de linfedema, foi realizada por meio de perimetria com trena acoplada a mola e peso, visando padronização da tensão nas medidas (Figura 3). O cálculo indireto do volume foi efetuado considerando a soma de seis cones, segundo critérios estabelecidos por Sander et al. (2002), com alto grau de confiabilidade quando comparado a volumetria com água, padrão ouro para essa mensuração (ICC = .91-.99). A fórmula a seguir, indica o cálculo utilizado para analisar a volumetria dos membros superiores.

$$
V=\frac{1}{12 \pi} \sum_{i=l}^{n} L\left(C_{i}^{2}+C_{i} C_{i-l}+C_{i-l^{2}}\right)
$$

Onde: $\mathrm{V}=$ Volume de segmento do membro, $\mathrm{L}=$ comprimento de cada segmento, $C_{i}$ e $C_{i-l}=$ circunferência em cada segmento i.

A presença de linfedema foi considerada em diferenças entre o membro homolateral a cirurgia e contralateral maior ou igual a $200 \mathrm{~mL}$ (Andersen et al., 2000). 


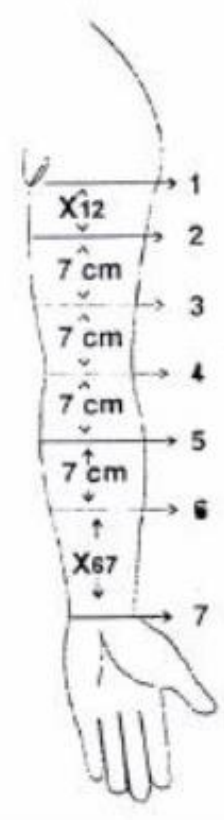

Figura 3. Imagem ilustrativa dos pontos utilizados para realização da medição da perimetria. Fonte: Meirelles, 1998.

Para classificação do tamanho da mama, foi realizado o cálculo da média das distâncias do mamilo ao sulco inframamário e do mamilo à margem esternal lateral (Figura 4), definindo três categorias: menos de $9 \mathrm{~cm}$ : mama pequena, 9 a $11 \mathrm{~cm}$ : mama média, e superior a $11 \mathrm{~cm}$ : mama grande (Sacchini et al., 1991).

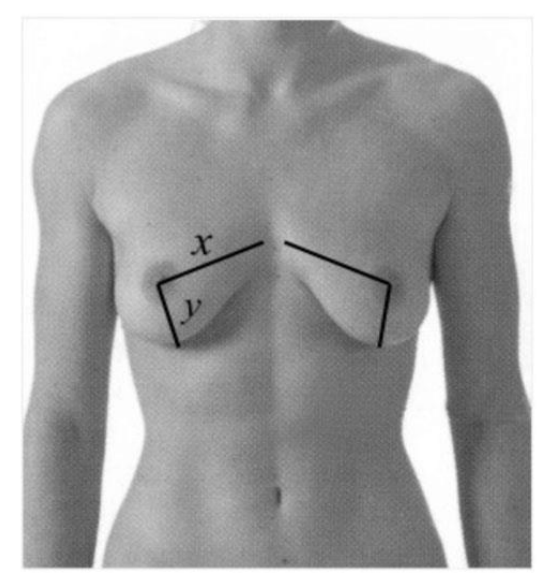

Figura 4. Imagem ilustrativa da avaliação do tamanho das mamas. Onde $\mathrm{x}$ é a distância do mamilo a margem esternal lateral e y é a distância do mamilo ao sulco inframamário. Fonte: Sacchini et al. (1991).

A análise do equilíbrio e da marcha foi efetuada com e sem a prótese mamária externa de polietileno (Associação Sempre Viva, Catanduva, São Paulo), sendo seu peso determinado por balança de precisão da marca Balmak Actilife (Balmak Indústria e Comércio Ltda., China, sensores 4 strain gages, peso máximo de $5 \mathrm{Kg}$ ), com tamanho equivalente a mama contralateral mensurado pelo índice de Sacchini (Figura 5). 


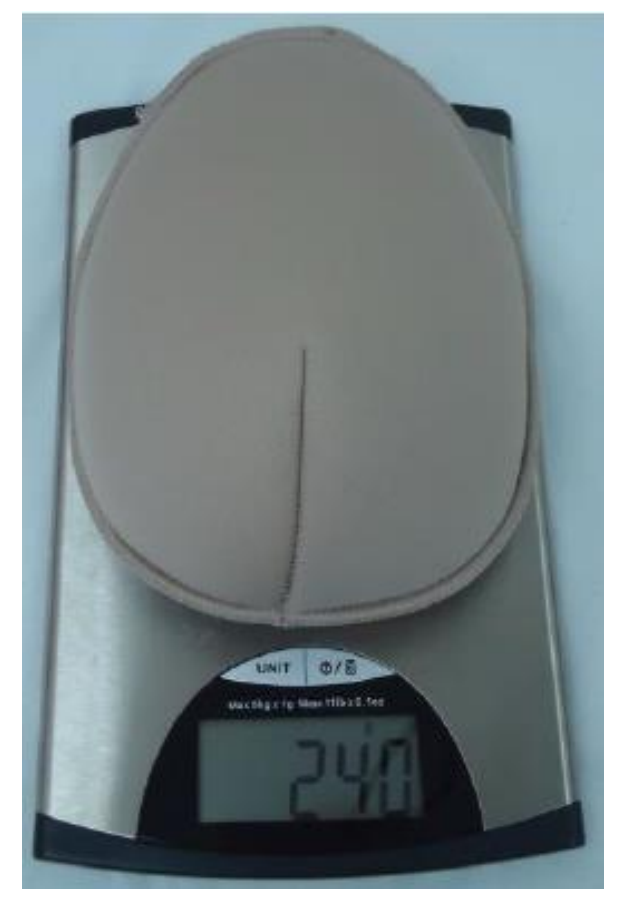

Figura 5. Foto ilustrativa da pesagem das próteses mamárias externas. Fonte: Arquivo pessoal.

\subsection{Avaliação do equilíbrio estático e da marcha}

A avaliação do equilíbrio estático e da marcha, foi efetuada usando o sistema Vicon System (VICON-MX-T40S, Oxford, Inglaterra), constituído por oito câmeras de infravermelho de 4 megapixels de resolução com uma frequência de aquisição de 100 $\mathrm{Hz}$, integrado a duas câmeras de vídeo para análise qualitativa, obtendo tomadas no plano frontal e sagital, com frequência de aquisição de 100 Hz (Riad et al., 2010). Antes de todas as coletas, foi realizado a calibração do sistema de acordo com o manual do fabricante.

O protocolo de marcadores Plug-in-gait Full Body (VICON, Oxford, Inglaterra) foi utilizado para obtenção das variáveis de interesse (Figura 6). Este protocolo consiste no posicionamento de 39 marcadores, além da necessidade de registro no sistema de algumas medidas antropométricas do sujeito: comprimento dos membros inferiores, largura dos tornozelos, largura dos joelhos, largura dos punhos, largura dos cotovelos, espessura da mão, e a distância do ombro, correspondente a acrômio até linha articular do ombro (Syczewska et al., 2011), sendo estas medidas avaliadas por meio de trena antropométrica e paquímetro de metal graduado em milímetros. 


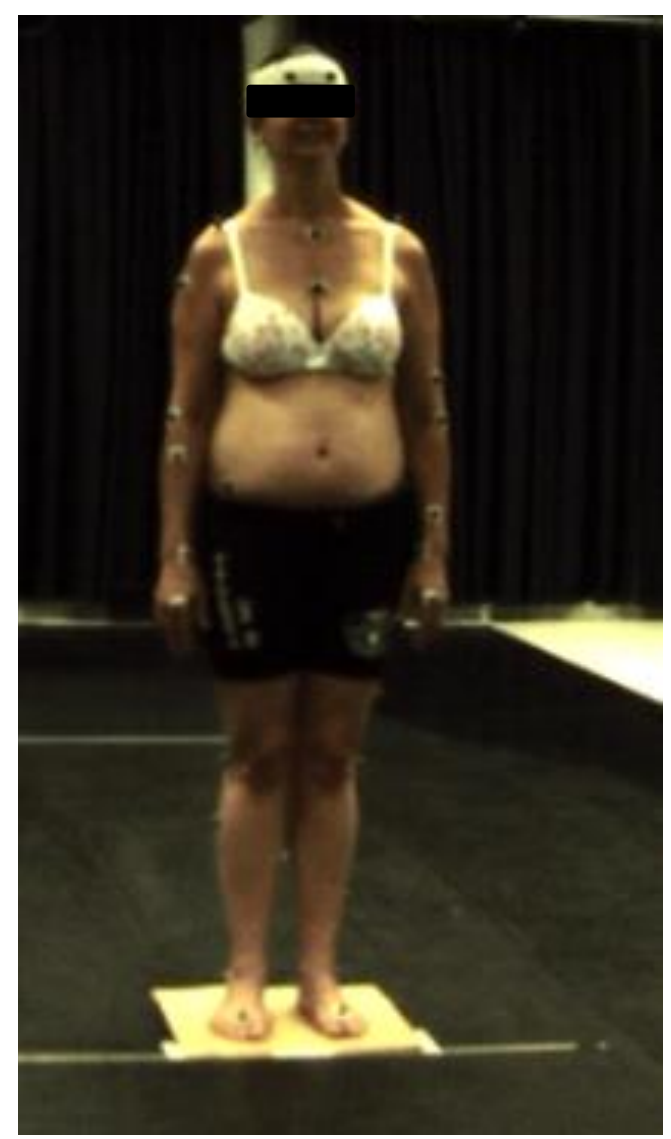

Figura 6. Imagem ilustrativa do pocisionamento dos marcadores do protocolo Plug-in-gait full body (VICON). Fonte: Arquivo Pessoal.

\subsubsection{Avaliação do equilíbrio estático}

As voluntárias de ambos os grupos foram avaliadas de olhos abertos e olhos fechados. Ainda no grupo GM, as voluntárias foram avaliadas com e sem o uso da prótese externa, sendo efetuadas três medidas para cada análise. A sequência foi designada de forma randomizada, por sorteio, utilizando-se de dois envelopes pardos, sendo um para "olhos abertos" ou "olhos fechados" e o outro "com prótese" e "sem prótese".

A voluntária foi posicionada de forma confortável, com a base de suporte não ultrapassando a largura dos ombros. Observando um ponto fixo, com 5,0 cm de diâmetro, posicionado a 3,0 m de distância, na altura dos olhos da voluntária, durante as análises com olhos abertos ilustrado na Figura 7 (Chiari, et al., 2002). 


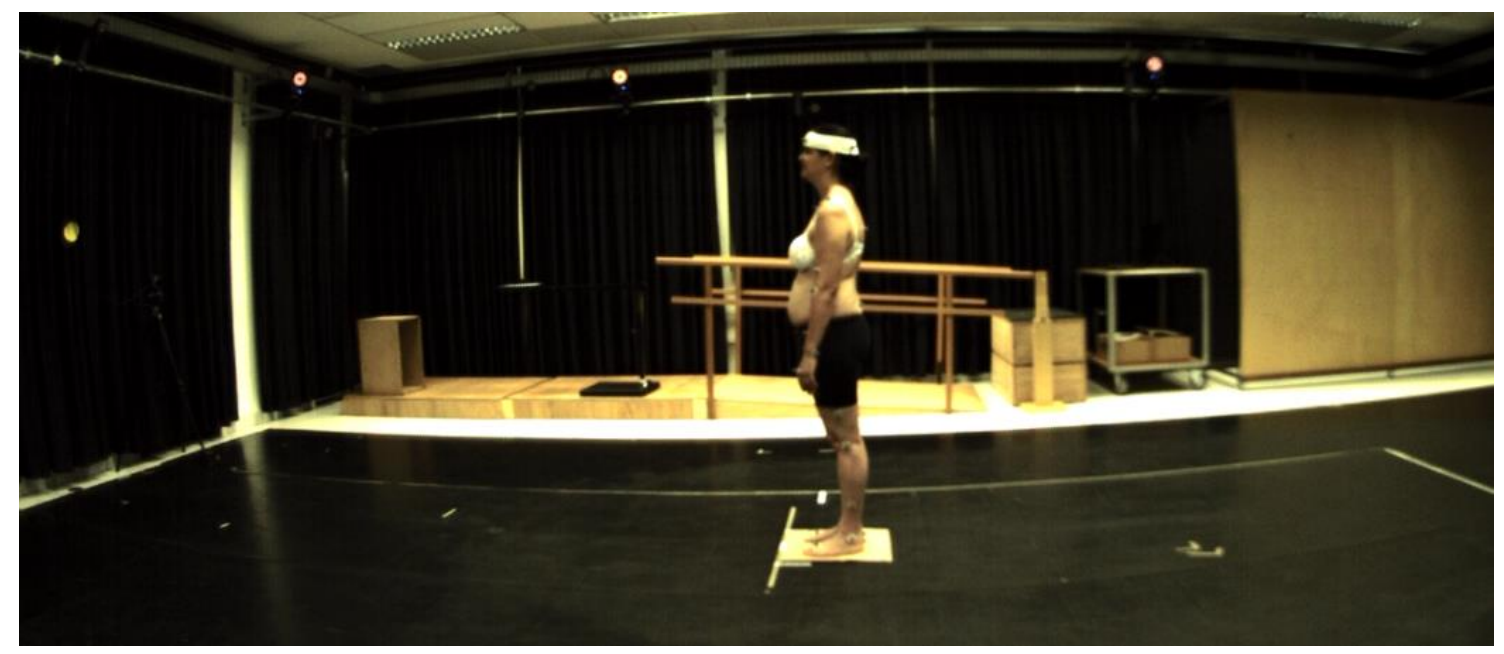

Figura 7. Foto ilustrativa da avaliação do equilíbrio estático com o sistema VICON. Fonte: Arquivo pessoal

O uso do protocolo de marcadores Plug-in-gait Full Body (VICON) e o processamento dos dados com o programa VICON (Vicon Nexus) possibilitou a mensuração do centro de massa. O tratamento matemático destes dados e as rotinas computacionais foram realizados em ambiente MatLab, afim de obter as variáveis de interesse. Desta forma, foi calculada a área da elipse através do centro de massa projetado no chão, com 95\% de confiança. Assim como o deslocamento anteroposterior (y) e médio-lateral (x) da área da elipse como demonstrado na Figura 8 (Hof et al., 2004; Jun Ling et al., 2009).

O deslocamento anteroposterior e médio-lateral, também foram mensurados através do ângulo da coluna, após processamento dos dados por meio software Nexus. 


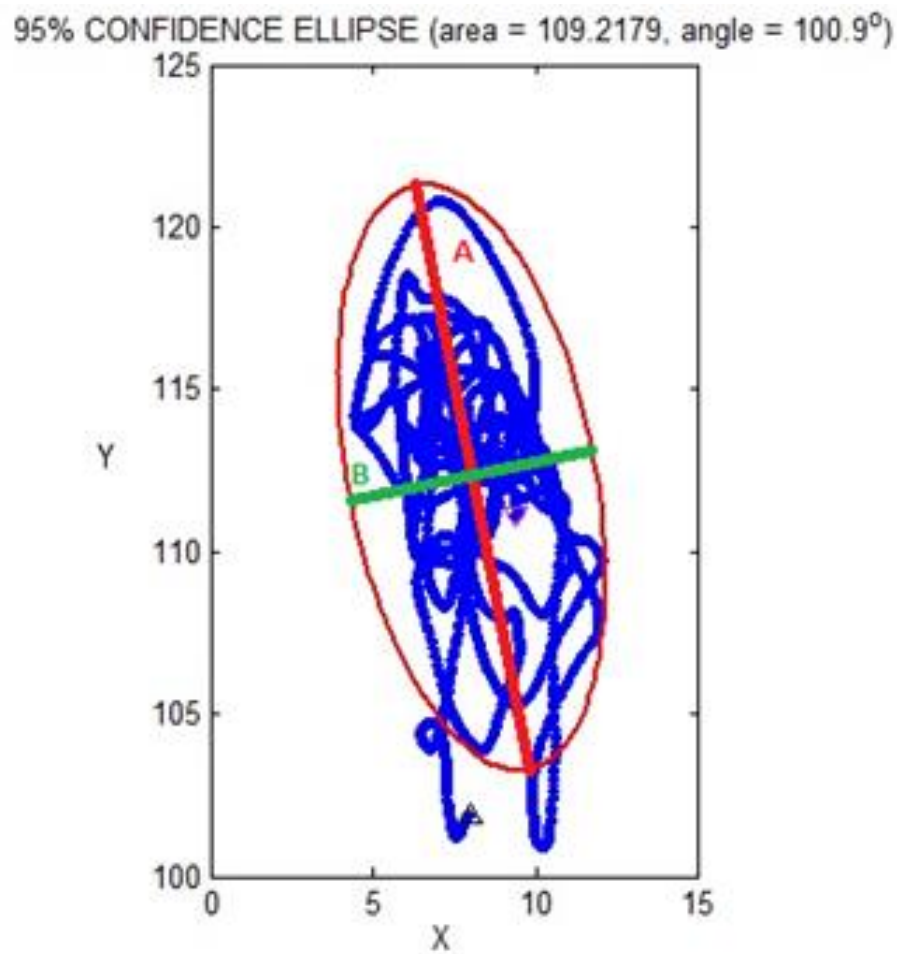

Figura 8. Área da elipse do deslocamento do centro de massa projetado no chão, com $95 \%$ de confiança. Onde A: deslocamento anteroposterior (semi eixo maior), B: deslocamento médio-lateral (semi eixo menor).

\subsubsection{Avaliação da marcha}

Para avaliação da marcha das voluntárias do grupo de mulheres mastectomizadas (GM), foram consideradas como variável o uso de prótese externa, sendo a sequência determinada de forma randomizada, por sorteio, utilizando-se de um envelope contendo "com prótese" e "sem prótese".

As voluntárias foram orientadas a sempre iniciar a marcha com o mesmo membro inferior, por uma distância de aproximadamente 10 metros, sobre material emborrachado, com repetição de três vezes por tarefa (Riad et.al., 2010).

Foram desconsiderados das análises o primeiro e último passo, visto que o objetivo não é avaliar a aceleração ou a desaceleração da marcha. Foram utilizadas duas passadas direitas para análise, sendo três toques de calcanhar direito (Figura 9). 


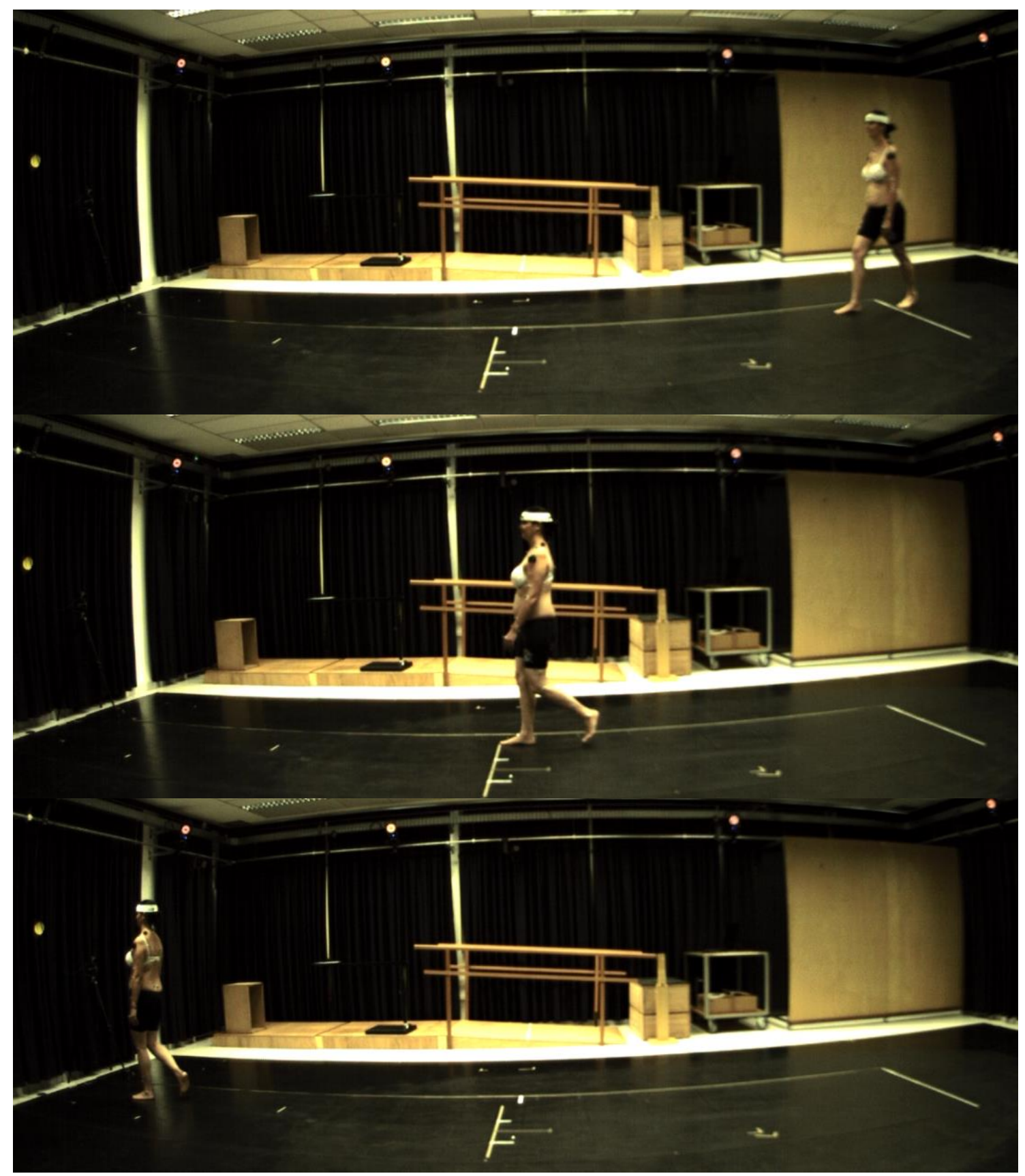

Figura 9. Foto ilustrativa da avaliação da marcha captada pelo sistema VICON. Fonte: Arquivo Pessoal

As variáveis espaço-temporais da marcha foram determinadas: comprimento do passo, comprimento da passada, largura do passo, tempo de suporte simples, tempo de suporte duplo, frequência e velocidade do passo (Carmo et al., 2012), por meio de marcadores fixados no calcâneo direito (RHEE), no calcâneo esquerdo (LHEE), no segundo metatarso direito (RTOD), e no segundo metatarso esquerdo (RTOE).

A avaliação do ângulo do ombro e da coluna durante a marcha foram processados por meio software Nexus. O cálculo destes ângulos foi efetuado da seguinte forma, segundo fabricante: 1) Coluna: flexão da coluna é o ângulo entre o eixo sagital 
do tórax e o eixo sagital da pelve, a rotação é mensurada como o ângulo entre o eixo longitudinal do tórax e o eixo sagital da pelve, em torno de um eixo frontal flutuante, as inclinações são os ângulos entre o eixo longitudinal da pelve, em torno de um eixo transversal flutuante; 2) Ombro: ângulo de flexão/extensão do ombro é calculado sobre um eixo paralelo ao eixo transversal do tórax, valores positivos significam projeção do braço à frente do corpo, portanto flexão do ombro. A rotação do ombro foi medida sobre o eixo longo do segmento do úmero e o eixo sagital do tórax em torno de um eixo frontal flutuante, valores positivos correspondem a rotação interna, abdução/rotação foram calculados entre o eixo transversal do úmero e do eixo transverso do tórax em torno de um eixo sagital flutuante.

A comparação da oscilação do ombro e da coluna durante a marcha, foi realizado em ambiente MataLab através de boxplot, utilizando-se de três passadas direitas que correspondem a $100 \%$ do ciclo da marcha.

\section{TRATAMENTO DOS DADOS}

O tamanho da amostra foi calculado com base no estudo de Crosbie et al., (2010), com um poder estatístico de $80 \%$ e um erro alfa de 0,05 , por meio do programa

Statemate 2 (Graphpad Software v 2.0), estabelecendo-se o número mínimo de 20 voluntários para cada grupo.

Os dados foram submetidos a análise exploratória que teve como objetivo básico sintetizar uma série de valores de mesma natureza, permitindo uma visão global da variação desses valores, organizando e descrevendo os dados de duas maneiras: em tabelas com medidas descritivas e em gráficos.

As variáveis foram organizadas em dois blocos para as devidas comparações: 1) intra-grupo grupo de mulheres mastectomizadas com prótese e sem prótese (GMCP versus GMSP) e 2) intergrupos (GMCP versus GC e GMSP versus GC).

Após a tabulação das variáveis foi aplicado o teste de normalidade de ShapiroWilk para analisar a distribuição. Diante de uma distribuição normal e relacionada, aplicou-se o teste $\mathrm{T}$ relacionado, e para amostras independentes, teste $\mathrm{T}$ independente. No caso de distribuição não paramétrica, foi aplicado Wilcoxon para variáveis relacionadas e Mann-Whitney, para variáveis independentes.

Em todos os cálculos foi fixado o nível crítico de $5 \%(\mathrm{p}<0,05)$, sendo o processamento dos dados efetuado pelo software SPSS, versão 17.0. 


\section{RESULTADOS}

\subsection{Resultados referentes à avaliação do equilíbrio estático}

Os resultados da avaliação do equilíbrio estático, relacionados à área da elipse formada pelo centro de massa projetado no chão com olhos abertos, apresentaram diferença significativa entre o GMCP e GC (0.003), e GMSP versus GC (0.001), sendo os grupos GMCP e GMSP apresentaram maior área. Na análise da área com os olhos fechados, houve diferença significativa entre o grupo GMCP versus o GC (0.001), e no grupo GMSP versus GC (0.006), com olhos fechados. Não foram encontradas diferenças significativas entre os grupos GMCP e GMSP, ou olhos abertos e olhos fechados dentro do mesmo grupo (Tabela 4).

Tabela 4. Valores referente a área da elipse formado pelo centro de massa projetado no chão em centímetros, do grupo de mulheres mastectomizadas com o uso da prótese mamária externa (GMCP), sem o uso da prótese mamária externa (GMSP) e grupo controle (GC), com olhos abertos (AO) e olhos fechados (OF).

\begin{tabular}{ccccccc}
\hline & GMCP & GMSP & $\boldsymbol{p}^{\mathbf{1}}$ & GC & $\boldsymbol{p}^{\mathbf{2}}$ & $\boldsymbol{p}^{\mathbf{3}}$ \\
\hline $\mathbf{O A}$ & 213.8 & 175.7 & 0,114 & 113.8 & 0.003 & 0.001 \\
& $(114.0$, & $(101.5$, & & $(64.4$, & & \\
& $320.7)$ & $243.2)$ & & $165.8)$ & & \\
$\mathbf{0 F}$ & 200.9 & 193.7 & 0,685 & 136.9 & 0.001 & 0.006 \\
& $(118.8$, & $(128.9$, & & $(90.2$, & & \\
& $282.7)$ & $274.2)$ & & $181.7)$ & & \\
& $\boldsymbol{p}^{\mathbf{4}}$ & $\boldsymbol{p}^{\mathbf{5}}$ & & $\boldsymbol{p}^{\mathbf{6}}$ & & \\
AO-OF & 0.607 & 0.014 & & 0.238 & &
\end{tabular}

Valores apresentados em mediana (primeiro quartil, terceiro quartil). ${ }^{1}$ GMCP vesrsus GMSP; ${ }^{2}$ GMCP versus GC; ${ }^{3}$ GMSP versus GC; ${ }^{4} \mathrm{OA}$ versus OF do GMCP; ${ }^{5}$ AO versus $\mathrm{OF}$ do GMSP; ${ }^{6} \mathrm{AO}$ versus $\mathrm{OF}$ do GC.

Com relação ao deslocamento nos eixos X (médio-lateral) e Y (anteroposterior), dentro da área da elipse do centro de massa projetado no chão, o grupo GMCP mostrou um maior deslocamento quando comparado ao GC, tanto de olhos abertos no eixo $\mathrm{X}$ ( $\mathrm{p}=0.021)$, quanto no eixo $\mathrm{Y}(\mathrm{p}=0.007)$, bem como com olhos fechados no eixo $\mathrm{Y}$ $(\mathrm{p}=0.027)$. O GMSP apresentou maior deslocamento apenas de olhos fechado no eixo $\mathrm{Y}$ versus o GC ( $\mathrm{p}=0.007)$. Quando confrontados o GMCP e GMSP, ou ainda dentro do 
mesmo grupo de olhos abertos e olhos fechados, não apresentaram diferença significativa.

Tabela 5. Valores referentes ao deslocamento médio-lateral (X) e anteroposterior (Y), encontrados dentro da área da elipse do centro de massa projetado no chão em centímetros, do grupo de mulheres mastectomizadas com o uso da prótese mamária externa (GMCP), sem o uso da prótese mamária externa (GMSP) e grupo controle (GC), com olhos abertos (AO) e olhos fechados (OF).

$\begin{array}{llllll}\text { GMCP } & \text { GMSP } & p^{1} & \text { GC } & p^{2} & p^{3}\end{array}$

\section{OA}

\begin{tabular}{ccccccc} 
Eixo X & 5.74 & 5.33 & 0.259 & 4.58 & 0.021 & 0.105 \\
& $(3.16)$ & $(2.74)$ & & $(2.37)$ & & \\
Eixo Y & 12.24 & 11.24 & & 9.98 & 0.005 & 0.065 \\
OF & $(4.83)$ & $(3.51)$ & 0.062 & $(4.01)$ & & \\
Eixo X & 5.86 & 5.72 & 0.483 & 4.87 & \multirow{2}{*}{0.058} & 0.099 \\
& $(3.19)$ & $(3.09)$ & & $(2.48)$ & & \\
Eixo Y & 12.31 & 13.16 & 0.209 & 10.62 & \multirow{2}{*}{0.027} & 0.007 \\
& $(5.08)$ & $(6.77)$ & & $(3.21)$ & & \\
\cline { 2 - 7 } & $\boldsymbol{p}^{\mathbf{4}}$ & $\boldsymbol{p}^{\mathbf{5}}$ & & $\boldsymbol{p}^{\mathbf{6}}$ & &
\end{tabular}

OA-OF:

Eixo X

$0.734 \quad 0.233 \quad 0.412$

AO-OF:

Eixo Y

$0.918 \quad 0.014 \quad 0.292$

Valores apresentados em média (desvio-padrão). ${ }^{1}$ GMCP vesrsus GMSP; ${ }^{2}$ GMCP versus GC; ${ }^{3} \mathrm{GMSP}$ versus GC; ${ }^{4} \mathrm{AO}$ versus $\mathrm{OF}$ do GMCP; ${ }^{5} \mathrm{AO}$ versus $\mathrm{OF}$ do GMSP; 6 $\mathrm{AO}$ versus $\mathrm{OF}$ do GC.

$\mathrm{Na}$ análise do ângulo da coluna, nos eixos x (anteroposterior) e y (médio-lateral), apenas o eixo y apresentou diferença significativa no GMCP confrontado com o GC (0.030). 
Tabela 6. Valores referentes ao ângulo da coluna anteroposterior (X) e médio-lateral (Y), em graus, do grupo de mulheres mastectomizadas com o uso da prótese mamária externa (GMCP), sem o uso da prótese mamária externa (GMSP) e grupo controle (GC).

\begin{tabular}{lllllll}
\hline & GMCP & GMSP & $\boldsymbol{p}^{\mathbf{1}}$ & $\mathbf{G C}$ & $\boldsymbol{p}^{\mathbf{2}}$ & $\boldsymbol{p}^{\mathbf{3}}$ \\
\hline \multirow{2}{*}{ Eixo X } & -9.76 & -9.65 & 0.838 & -6.31 & 0.139 & 0.149 \\
& $(12.49)$ & $(12.31)$ & & $(11.88)$ & & \\
Eixo Y & -1.72 & -1.34 & 0.558 & -0.61 & 0.030 & 0.345 \\
& $(2.62)$ & $(5.91)$ & & $(3.21)$ & &
\end{tabular}

Valores apresentados em média (desvio-padrão). ${ }^{1}$ GMCP vesrsus GMSP; ${ }^{2}$ GMCP versus GC; ${ }^{3}$ GMSP versus GC.

\subsection{Resultados referentes à avaliação da marcha}

$\mathrm{Na}$ análise dos parâmetros espaço temporais da marcha, houve diferença significativa entre o GMCP versus o GC para comprimento do passo, comprimento da passada, largura do passo, tempo de suporte duplo, velocidade $(<0.001)$ e frequência (0.001). Ao confrontar o GMSP e o GC houve diferença significativa nos mesmos parâmetros. A utilização da prótese mamária externa não alterou os parâmetros espaço temporal da marcha (Tabela 7). 
Tabela 7. Valores referentes aos parâmetros espaço temporais da marcha do grupo de mulheres mastectomizadas com o uso da prótese mamária externa (GMCP), sem o uso da prótese mamária externa (GMSP) e grupo controle (GC).

\begin{tabular}{|c|c|c|c|c|c|c|}
\hline & GMCP & GMSP & $p^{1}$ & GC & $p^{2}$ & $p^{3}$ \\
\hline $\begin{array}{l}\text { Comprimento } \\
\text { do Passo (m) }\end{array}$ & $\begin{array}{c}0.56 \\
(0.04)\end{array}$ & $\begin{array}{c}0.56 \\
(0.04)\end{array}$ & 0.173 & $\begin{array}{c}0.59 \\
(0.04)\end{array}$ & $<0.001$ & 0.002 \\
\hline
\end{tabular}

\section{Comprimento}

\begin{tabular}{|c|c|c|c|c|c|}
\hline da Passada & & & 0.125 & & $<0.001$ \\
\hline (m) & (0.09) & $(0.08)$ & & $(0.04)$ & \\
\hline
\end{tabular}

$\begin{array}{lcccccc}\text { Largura do } & & & & & & \\ \text { Passo (m) } & 0.54 & 0.55 & 0.58 & <0.001 & 0.002\end{array}$

Tempo de

$\begin{array}{ccccccc}\text { Suporte } & 0.41 & 0.41 & 0.09 & 0.41 & 0.552 & 0.917 \\ \text { Simples (s) } & (0.04) & (0.03) & & (0.03) & & \end{array}$

Tempo de

$\begin{array}{ccccccc}\text { Suporte Duplo } & 0.15 & 0.15 & 0.12 & 0.12 & <0.001 & <0.001 \\ (\mathrm{~s}) & (0.02) & (0.02) & & (0.02) & & \end{array}$

\begin{tabular}{|c|c|c|c|c|c|c|}
\hline $\begin{array}{l}\text { Frequência } \\
\text { (passos/min) }\end{array}$ & $\begin{array}{l}106.13 \\
(8.86)\end{array}$ & $\begin{array}{l}106.92 \\
(8.21)\end{array}$ & 0.127 & $\begin{array}{l}112.69 \\
(9.89)\end{array}$ & 0.001 & 0.005 \\
\hline
\end{tabular}

$\begin{array}{lcccccc}\text { Velocidade do } & 0.98 & 1.0(0.09) & 0.052 & 1.12 & <0.001 & <0.001 \\ \text { Passo (m/s) } & (0.12) & & & (0.16) & & \end{array}$

Valores apresentados em média (desvio-padrão). ${ }^{1}$ GMCP versus GMSP; ${ }^{2}$ GMCP versus GC; ${ }^{3}$ GMSP versus GC. Abreviações: m (metros), s (segundos).

A avaliação da diferença entre o ângulo máximo e mínimo do ombro na oscilação dos membros superiores durante a marcha, mostrou não existir diferença significativa entre o membro superior direito (D) e esquerdo (E) do grupo GC, isto nos permitiu utilizar apenas um membro superior para comparação com o grupo GM. 
Entretanto o grupo GM foi dividido em membro superior homolateral à cirurgia (CI) e membro superior contralateral à cirurgia (CL). O GMCP apresentou diferença significativa entre o CI e CL para os movimentos de flexão/extensão $(<0.001)$, e abdução/adução (0.008), o mesmo ocorre no GMSP, flexão/extensão (0.002) e abdução/adução (0.037), em todos os casos que houve diferença significativa entre os lados, o membro superior homolateral à cirurgia apresentou menor oscilação para o movimento que o membro superior contralateral à cirurgia.

Tabela 8. Diferença ente o ângulo máximo e mínimo do ombro durante a marcha, para os movimentos flexão/extensão (F/E), abdução/adução (A/A) e rotação interna/rotação externa (RI/RE), do grupo de mulheres mastectomizadas com o uso da prótese mamária externa (GMCP), sem o uso da prótese mamária externa (GMSP), lado homolateral à cirurgia $(\mathrm{CI})$ e contralateral à cirurgia $(\mathrm{CL})$ e grupo controle (GC) lado direito $(\mathrm{D})$ e lado esquerdo (E).

\begin{tabular}{|c|c|c|c|c|c|c|c|c|c|}
\hline & \multicolumn{2}{|c|}{ GMCP } & \multirow[b]{2}{*}{$p^{1}$} & \multicolumn{2}{|c|}{ GMSP } & \multicolumn{4}{|c|}{ GC } \\
\hline & CI & CL & & CI & CL & $p^{2}$ & D & $\mathbf{E}$ & $p^{3}$ \\
\hline $\mathbf{F} / \mathbf{E}$ & $\begin{array}{l}21.6 \\
(9.6)\end{array}$ & $\begin{array}{c}31.4 \\
(11.6)\end{array}$ & $<0.001$ & $\begin{array}{c}24.6 \\
(10.3)\end{array}$ & $\begin{array}{c}32.1 \\
(12.2)\end{array}$ & 0.002 & $\begin{array}{l}28.9 \\
(8.7)\end{array}$ & $\begin{array}{c}28.0 \\
(11.6)\end{array}$ & 0.566 \\
\hline $\mathbf{A} / \mathbf{A}$ & $\begin{array}{l}23.7 \\
(6.2)\end{array}$ & $\begin{array}{l}27.3 \\
(6.9)\end{array}$ & 0.008 & $\begin{array}{l}25.8 \\
(8.6)\end{array}$ & $\begin{array}{l}27.5 \\
(7.9)\end{array}$ & 0.037 & $\begin{array}{l}24.5 \\
(4.3)\end{array}$ & $\begin{array}{l}23.3 \\
(4.7)\end{array}$ & 0.117 \\
\hline $\begin{array}{l}\text { RI/ } \\
\text { RE }\end{array}$ & $\begin{array}{c}56.6 \\
(15.0)\end{array}$ & $\begin{array}{c}58.3 \\
(16.5)\end{array}$ & 0.689 & $\begin{array}{c}58.4 \\
(18.5)\end{array}$ & $\begin{array}{c}59.8 \\
(17.6)\end{array}$ & 0.676 & $\begin{array}{c}63.7 \\
(17.7)\end{array}$ & $\begin{array}{c}64.0 \\
(13.3)\end{array}$ & 0.932 \\
\hline
\end{tabular}

Valores apresentados em média (desvio-padrão), em graus. ${ }^{1}$ GMCP: CI versus CL, ${ }^{2}$ GMSP: CI versus CL, ${ }^{3} \mathrm{GC}$ : D versus E.

A oscilação do ombro no plano sagital durante o ciclo da marcha está representada na Figura 10. Na Figura 10A, é possível observar que o grupo GC apresenta semelhança no grau de movimentação do ombro no plano sagital, o mesmo não ocorre no grupo GMCP (Figura 10B), onde o ombro homolateral à cirurgia apresenta menor angulação de movimentação do ombro, quando comparado ao ombro contralateral à cirurgia no plano sagital, durante o ciclo da marcha. Foram encontradas diferenças significativas entre o ombro homolateral à cirurgia do grupo GMCP versus o GC (Figura 10C), correspondente aos $8 \%$ iniciais e finais do ciclo, assim como entre $45 \%$ e $55 \%$ do ciclo, estes momentos representam a fase de apoio do membro inferior contralateral ao membro superior em movimento. 

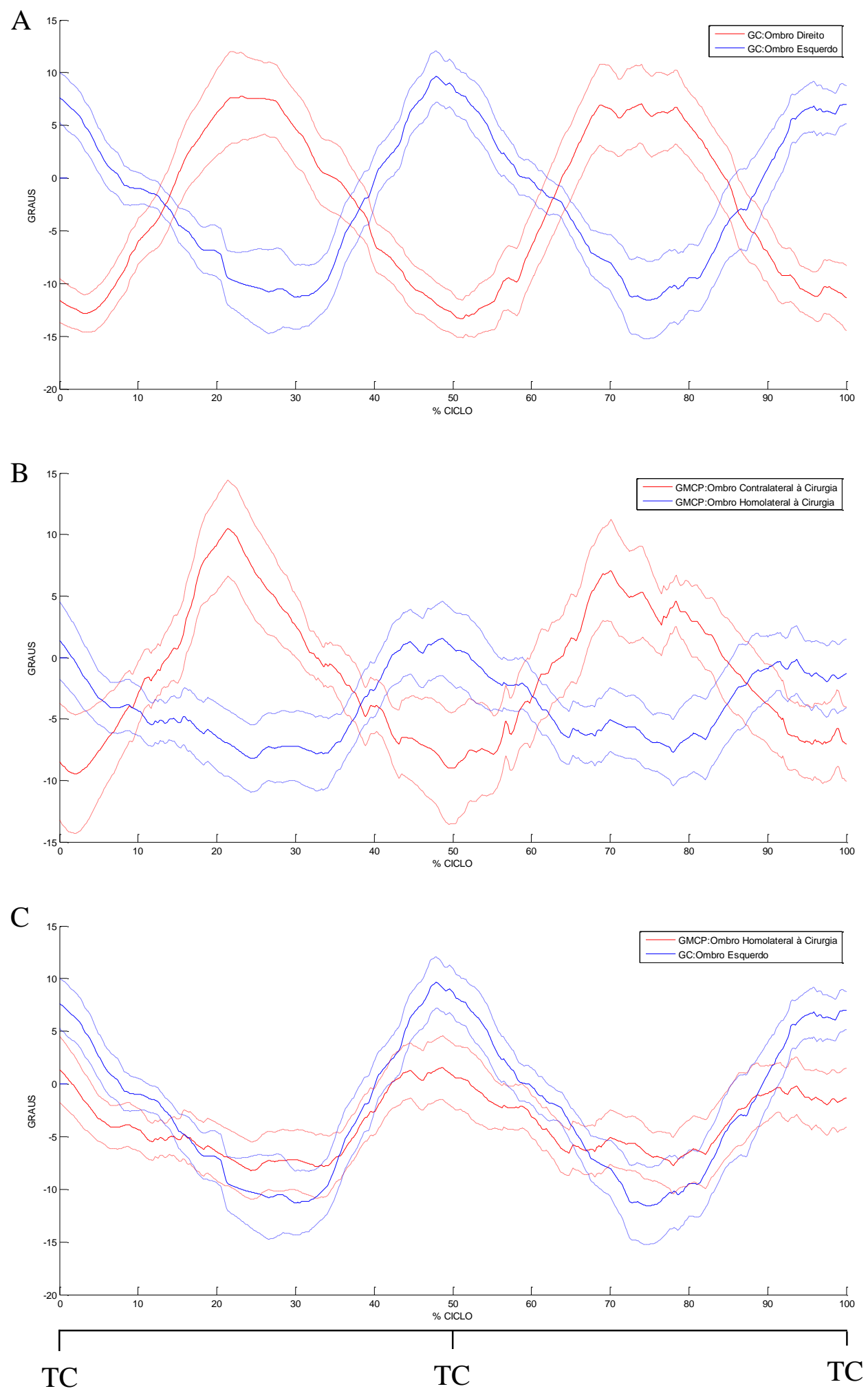

Figura 10. Oscilação do ombro no plano sagital durante o ciclo da marcha. A: Oscilação do ombro direito versus ombro esquerdo do grupo controle (GC). B: Oscilação do ombro homolateral à cirurgia versus ombro contralateral à cirurgia do grupo de mastectomizadas (GMCP). C: Oscilação do ombro esquerdo do grupo controle (GC) e ombro homolateral a cirurgia do grupo de mastectomizadas (GMCP).Apresentado em mediana (primeiro quartil, terceiro quartil). Abreviação, TC: toque de calcanhar. 
A Figura 11 aponta a oscilação do ombro no plano coronal durante o ciclo da marcha. A angulação alcançada pelo membro superior direito e esquerdo do grupo GC (Figura 11A) e membro superior homolateral à cirurgia e contralateral à cirurgia do grupo GMCP, durante o ciclo da marcha são semelhantes. Não foram encontradas diferenças significativas entre o ombro homolateral a cirurgia do grupo GMCP versus o GC (Figura 11C).

A oscilação do ombro no plano transversal está representada na Figura 12. Na Figura 12A, é possível observar que o grupo GC apresenta semelhança no grau de movimentação do ombro, o mesmo não ocorre no grupo GMCP (Figura 12B), onde o ombro homolateral à cirurgia apresenta menor angulação de movimentação do ombro, quando comparado ao ombro contralateral à cirurgia no plano transversal, durante o ciclo da marcha. Foram encontradas diferenças significativas entre o ombro homolateral à cirurgia do grupo GMCP versus o GC (Figura 12C), nos intervalos de 12-38\% e 65$85 \%$ do ciclo, após o toque de calcanhar do membro inferior contralateral ao membro superior apontado. 

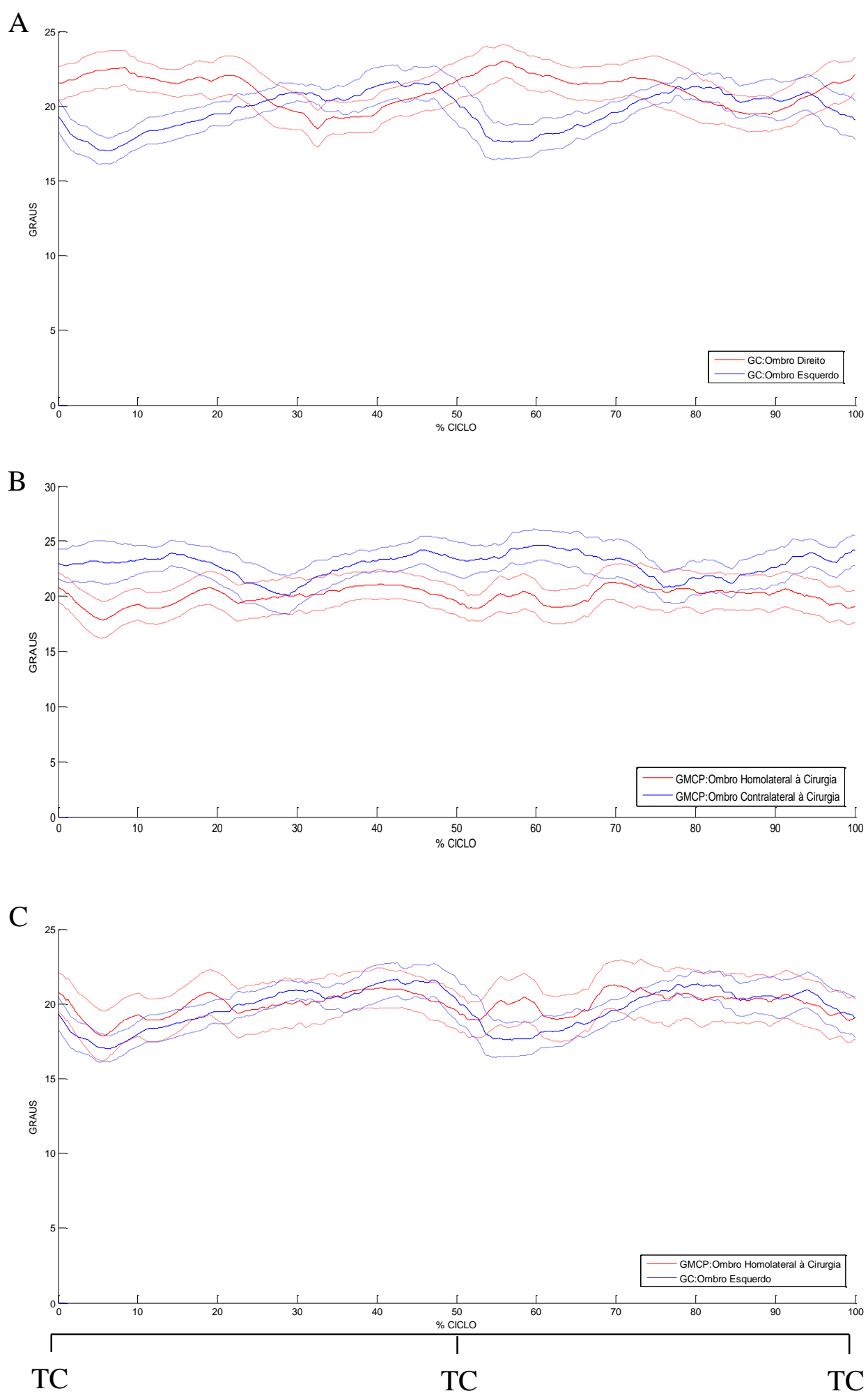

Figura 11. Oscilação do ombro no plano coronal durante o ciclo da marcha. A: Oscilação do ombro direito versus ombro esquerdo do grupo controle (GC). B: Oscilação do ombro homolateral à cirurgia versus ombro contralateral à cirurgia do grupo de mastectomizadas (GMCP). C: Oscilação do ombro esquerdo do grupo controle (GC) e ombro homolateral a cirurgia do grupo de mastectomizadas (GMCP). Apresentado em mediana (primeiro quartil, terceiro quartil). Abreviação, TC: toque de calcanhar. 

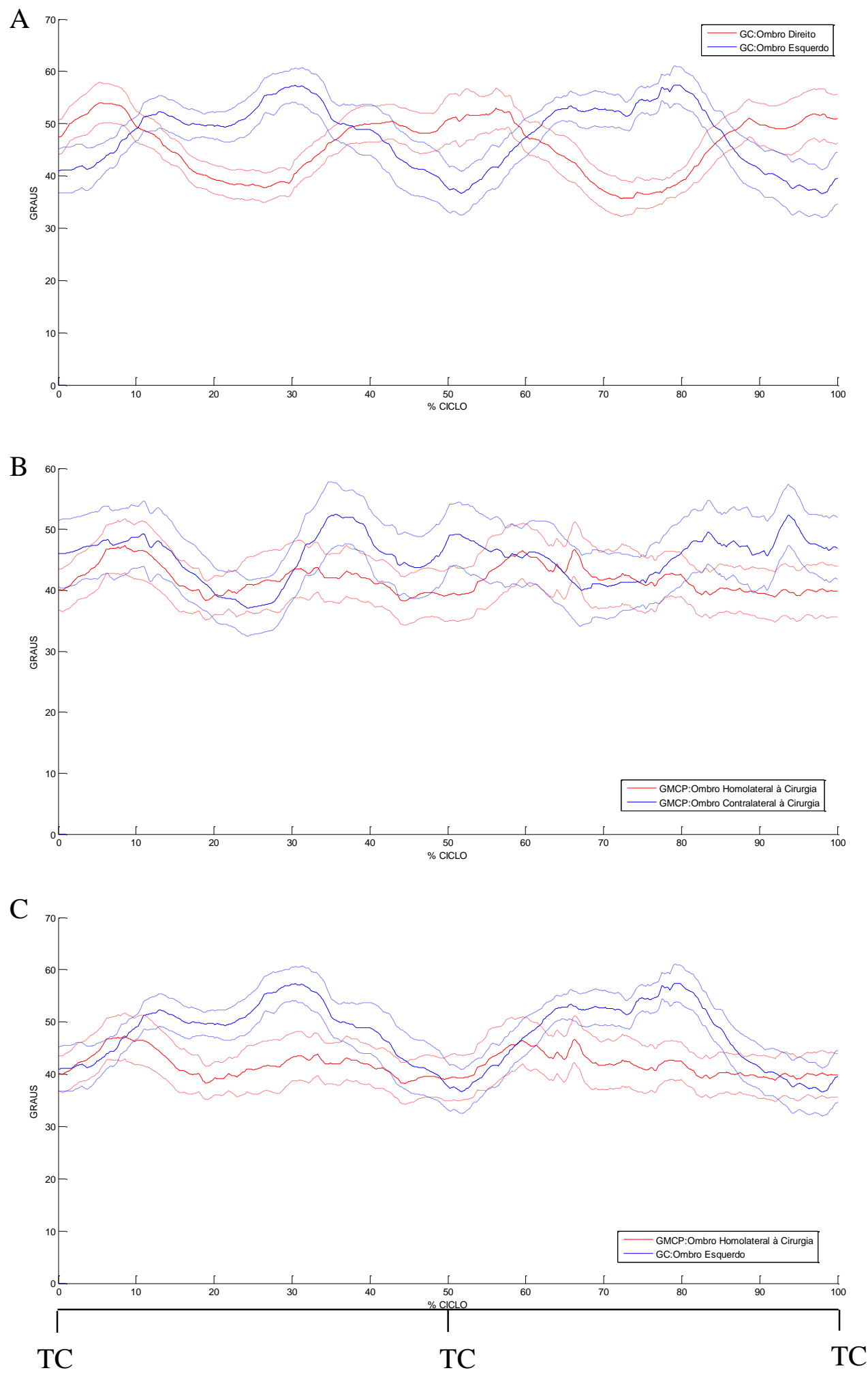

Figura 12- Oscilação do ombro no plano transversal durante o ciclo da marcha. A: Oscilação do ombro direito versus ombro esquerdo do grupo controle (GC). B: Oscilação do ombro homolateral à cirurgia versus ombro contralateral à cirurgia do grupo de mastectomizadas (GMCP). C: Oscilação do ombro esquerdo do grupo controle (GC) e ombro homolateral a cirurgia do grupo de mastectomizadas (GMCP). Apresentado em mediana (primeiro quartil, terceiro quartil). Abreviação, TC: toque de calcanhar. 
A Figura 13 representa a oscilação do ângulo da coluna no plano sagital, durante o ciclo da marcha. Não foram encontradas diferenças significativas em nenhum momento do ciclo da marcha, comparados o grupo GMCP e grupo GC (Figura 13C). A mudança da angulação durante o ciclo da marcha para os grupos GMCP e GC foram semelhantes (Figura 13A-B).

A oscilação do ângulo da coluna no plano frontal (Figura 14) apresentaram diferença significativa nos intervalos de $30-38 \%$ e $80-90 \%$ do ciclo da marcha (Figura 14C), correspondente a fase de balaço do membro inferior contralateral ao membro superior apontado. Nos instantes de $20-40 \%$ e $70-90 \%$, a oscilação em graus médiolateral da coluna no grupo GMCP (Figura 14B), é aparentemente menor que no grupo GC (Figura 14A). 

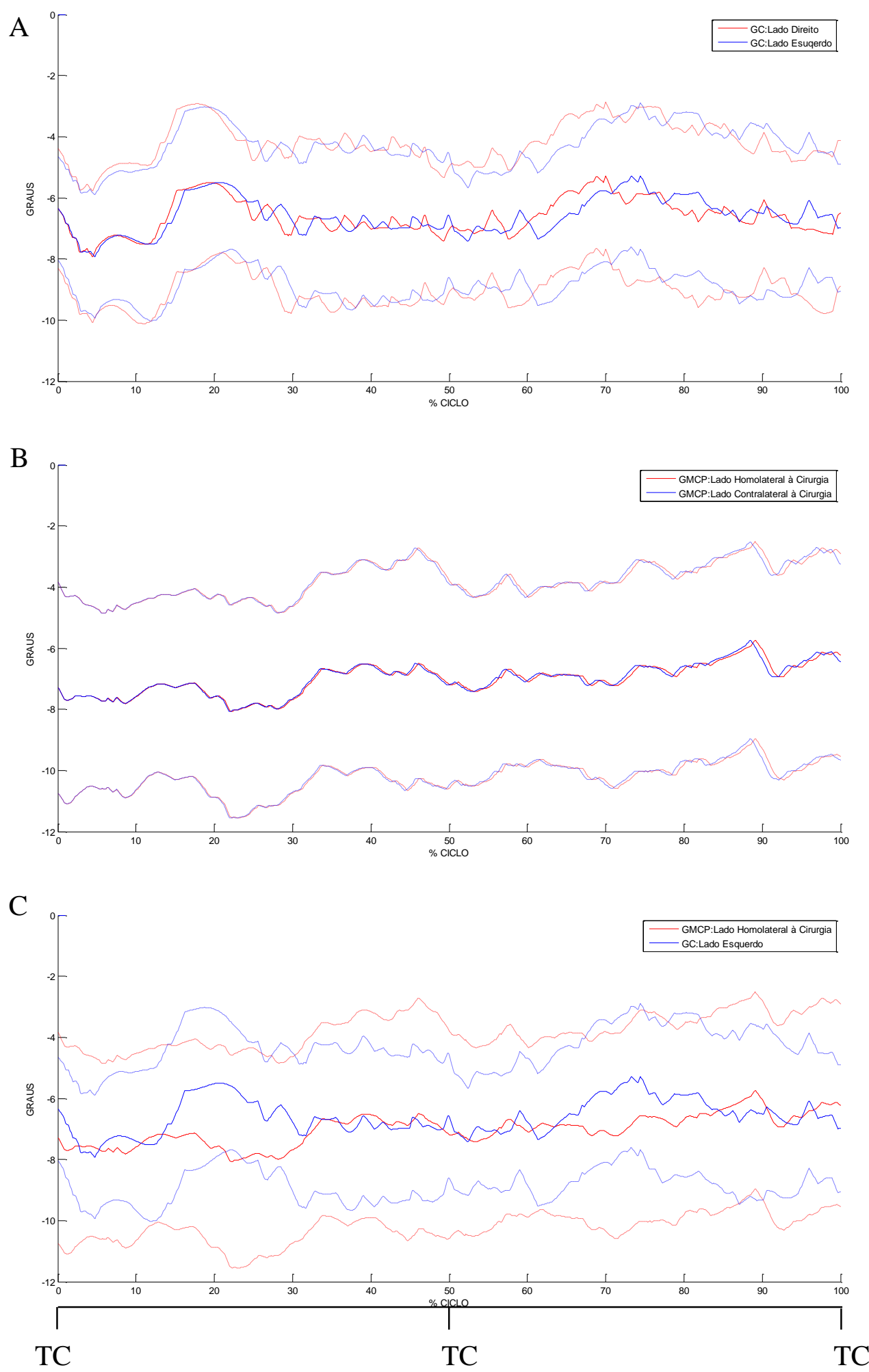

Figura 13. Oscilação do ângulo da coluna no plano sagital durante o ciclo da marcha. A: Oscilação da coluna anteroposterior do grupo controle (GC). B: Oscilação anteroposterior do grupo de mastectomizadas (GMCP). C: Oscilação anteroposterior do grupo controle (GC) versus grupo de mastectomizadas (GMCP). Apresentado em mediana (primeiro quartil, terceiro quartil). Abreviação, TC: toque de calcanhar. 

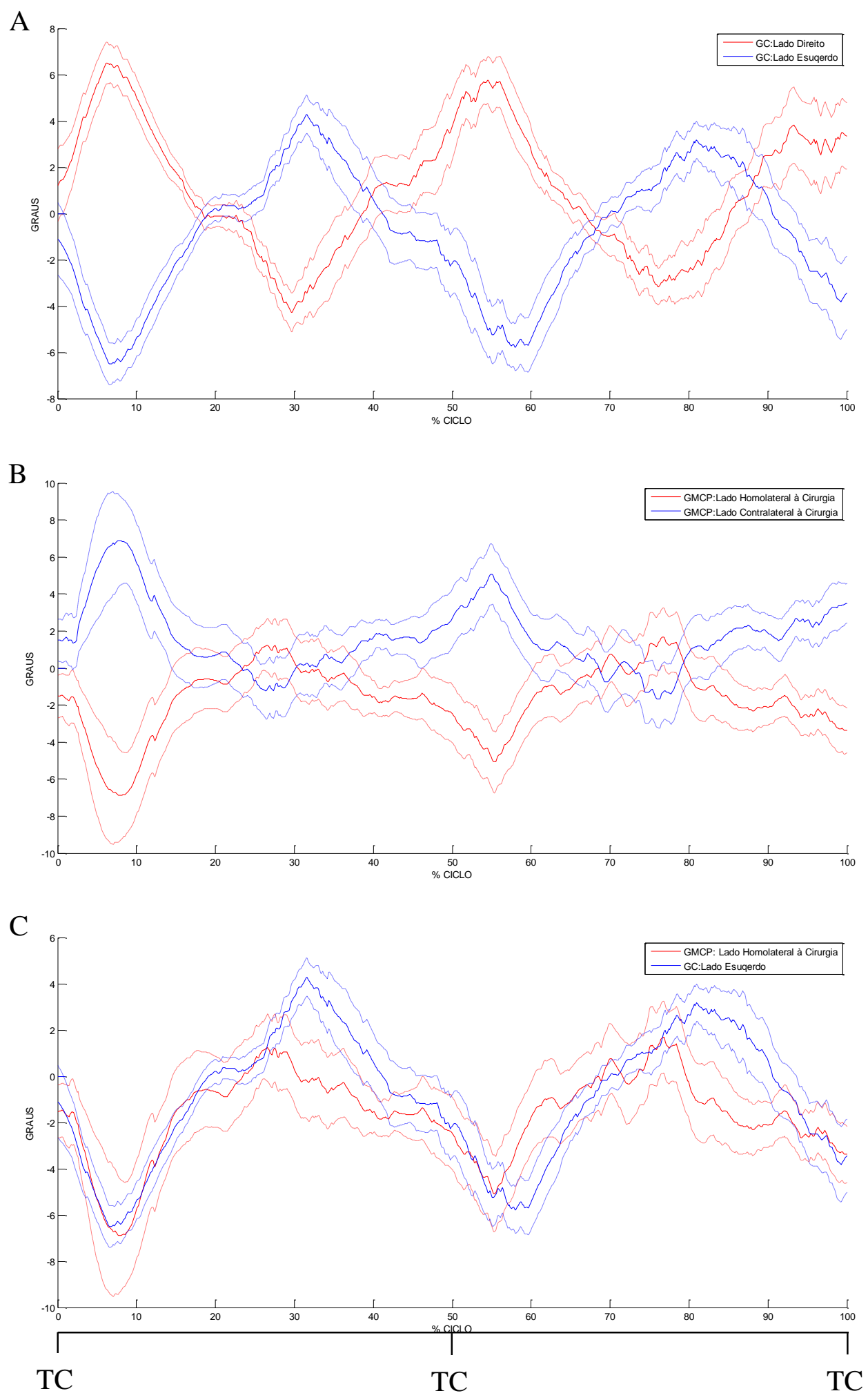

Figura 14. Oscilação do ângulo da coluna no plano frontal durante o ciclo da marcha. A: Oscilação da coluna médio-lateral do grupo controle (GC). B: Oscilação médiolateral do grupo de mastectomizadas (GMCP). C: Oscilação médio-lateral do ângulo da coluna do grupo controle (GC) versus grupo de mastectomizadas (GMCP). Apresentado em mediana (primeiro quartil, terceiro quartil). Abreviação, TC: toque de calcanhar. 


\section{Discusesana}




\section{DISCUSSÃO}

O presente estudo avaliou a função física com relação ao equilíbrio e a marcha de pacientes após a mastectomia unilateral para o tratamento do câncer de mama comparado com mulheres sem a doença. Os resultados indicam comprometimento do controle postural e da marcha.

Com relação ao equilíbrio das mulheres submetidas ao tratamento do câncer de mama, os resultados demostraram um pior controle deste, quando comparada as mulheres controle, já que a mulheres mastectomizadas apresentam maior área da elipse formada pelo centro de massa projetado no chão, e maior deslocamento ântero-posterior e médio lateral também do centro de massa na posição estática.

A postura apresenta característica dinâmica visto que as partes do corpo se adaptam constantemente, em resposta a estímulos recebidos, refletindo corporalmente experiências vivenciadas (Braccialli e Vilarta, 2001).

A mulher submetida à remoção cirúrgica unilateral da mama apresenta uma série de alterações posturais (Rostkowska, Bak e Samborski, 2006), entretanto as assimetrias posturais estáticas e dinâmicas decorrentes do tratamento ainda são pouco estudadas.

Alteração do controle postural pode ser decorrente da mudança do centro de gravidade, podendo ter como causa o tamanho das mamas (Fernandes, 2007), sendo maior em mulheres com hipertrofia mamária, fato observado em estudo que apontou menor área de oscilação do centro de pressão em mulheres submetidas a mamoplastia redutora (Barbosa 2012, 2013).

Mulheres com hipertrofia mamária apresentam maior área do centro de pressão, quando comparado a mulheres sem hipertrofia mamária (Barbosa et al., 2012), o maior tamanho das mamas, também alterou significativamente o controle postural, mulheres com hipertrofia mamária após serem submetidas a cirurgia de mamoplastia redutora, apresentam um melhor controle postural, bem como menor área de oscilação do centro de pressão (Barbosa et al., 2013).

No presente estudo foram incluídas apenas mulheres com mamas médias e grandes, de acordo com critérios estabelecidos por Sacchini (1991), por configurar maior possibilidade de alterações posturais decorrentes da amputação unilateral da mama. Este fato foi confirmado pelos resultados referentes ao equilíbrio postural onde existe maior comprometimento nas mulheres mastectomizadas em relação as mulheres sem a doença. 
Nossos achados corroboram com estudos (Ciesla et al., 2000, Montezuma et al., 2014) que observaram que a assimetria causada pela mastectomia unilateral, pode alterar significativamente o controle postural, além da postura. A novidade do presente estudo consiste na avaliação do deslocamento do centro de massa, bem como considerar o uso da prótese externa, tão comum no cotidiano destas mulheres.

Cerca de $90 \%$ das mulheres submetidas à cirurgia de mastectomia para o câncer de mama, que não são submetidas a reconstrução imediata, optam pelo uso da prótese mamária externa, que promove um aumento da confiança e da autoestima, assim como melhora da imagem corporal (Fitch et al., 2012), além de trazer grande satisfação à essas mulheres (Borghesan et al., 2014).

Estudos que exploram a influência da prótese mamária externa no equilíbrio e na marcha ainda são escassos. Por este motivo, a influência da prótese mamária externa no equilíbrio estático e dinâmico de mulheres submetidas a mastectomia unilateral foi considerada neste estudo.

O incremento de carga unilateral em adultos foi capaz de causar uma assimetria postural, juntamente com um deslocamento do centro de massa, quanto maior a carga unilateral, maior a velocidade do centro de pressão e consequentemente, pior a estabilidade postural (Anker et al., 2008). Nossos resultados mostraram que na posição estática, o deslocamento anteroposterior e médio-lateral das mulheres mastectomizadas fazendo uso da prótese mamária externa foi maior que no grupo controle, o mesmo não ocorre sem a prótese mamaria externa. É provável que a carga imposta pela prótese tenha produzido um desequilíbrio imediato, pela possível adaptação a condição imposta pela cirurgia, ocasionando o aumento da oscilação postural observada. Estudos longitudinais do uso da prótese mamária externa são necessários para avaliar o comportamento postural e de equilíbrio, com o uso prolongado da prótese.

O tratamento do câncer envolvendo procedimento cirúrgico bem como a terapia adjuvante podem interferir no controle postural de mulheres mastectomizadas, especialmente a quimioterapia (Wampler et al., 2007). As voluntárias avaliadas no presente estudo foram submetidas a quimioterapia adjuvante, fato que também pode ter contribuído para os achados encontrados.

Para uma análise mais completa do controle postural, é importante uma investigação estática, bem como dinâmica (Winter, 1995), sendo provável a alteração de ambas decorrentes de assimetrias (Gur et al., 2015; Syczewska et al., 2012), fato observado no presente estudo. O resultado apontou que mulheres mastectomizadas 
tiveram maior prejuízo nas variáveis espaço temporais da marcha, assim como uma menor oscilação do membro superior homolateral à cirurgia, e do tronco durante a marcha.

A maioria das mulheres submetidas ao tratamento cirúrgico para tratamento do câncer de mama apresentam comprometimento da função dos membros superiores (Teo et al., 2015). O questionário Disabilities of Arm, Shoulder and Hand (DASH) é recomendado para avaliação da função dos membros superiores em mulheres após tratamento para o câncer de mama (Harrington et al., 2014). No presente estudo, as mulheres mastectomizadas apresentaram um score para o DASH significativamente maior que as mulheres sem a doença, mostrando um maior comprometimento da função dos membros superiores.

A amplitude de movimento do ombro homolateral à cirurgia de mastectomia é reduzida (Flores et al., 2014), bem como existem alterações na cinemática do ombro e da cintura escapular (Crosbie et al., 2012).

O interesse pelo estudo das funções de tronco, cabeça e membros superiores durante a marcha é recente, e a quantificação desses segmentos ainda é limitada (Kubo et al. 2006). Ao analisar a marcha nos padrões de normalidade, apenas o estudo da pelve e membros inferiores pode ser suficiente para uma caracterização, mas ao estudar a marcha em mulheres submetidas a mastectomia, adicionando todos os elementos complicadores do movimento das articulações do tronco superior, decorrentes desta cirurgia, as mulheres passam a utilizar mecanismos compensatórios destes movimentos, sendo assim, cabeça, tronco e membros superiores não poderiam ter papel coadjuvante nesta análise (Carmo et al. 2009).

A oscilação dos membros superiores desempenha um papel estabilizador durante a marcha, reduzindo o custo metabólico da marcha (Ortega et al., 2007; Umberger, 2008;), fato que aponta a importância em se levar em consideração a avaliação da oscilação dos membros superiores durante a marcha, em mulheres mastectomizadas, efetuada no presente estudo.

Para investigação da contribuição da oscilação dos membros superiores no desempenho de tarefas que exigissem equilíbrio e mobilidade, foram aplicados testes com os membros superiores livres para movimentação e restritos ao movimento. Os resultados mostraram melhor desempenho nos testes de equilíbrio e mobilidade clínica com os membros superiores livres, o que sugere que a influência dos membros superiores durante tarefas dinâmicas é suficientemente grande para ser detectado 
(Milosevic et al., 2011). Provavelmente, pelo fato que os membros superiores apresentam movimentos reacionais em resposta a perda de equilíbrio e também durante a marcha (Roos et al., 2007)

$\mathrm{O}$ ato de caminhar requer coordenação de todo o corpo, e o balanço dos braços é um complemento para o torque de reação do solo na postura ortostática. A oscilação dos membros superiores durante a marcha aperfeiçoa o movimento do membro inferior, minimizando um aumento de torque sobre as articulações e estruturas do corpo, enquanto controla o tronco e membros inferiores para seguir a trajetória projetada (Park et al., 2008)

O padrão de marcha é influenciado pela mudança no balanço dos membros superiores, sendo que a oscilação diminuída promove diminuição da velocidade da marcha e comprometimento da frequência de passada (Eke-Okoro et al., 1997), além de maior gasto energético (Ortega et al., 2007). Nossos achados demonstram que a redução da oscilação dos membros superiores pode ter influenciado na velocidade e frequência da marcha, já que estes parâmetros foram menores nas mulheres mastectomizadas.

Pacientes com câncer apresentam menor desempenho funcional que indivíduos saudáveis da mesma idade, além de menor velocidade da marcha, menor força de membros inferiores, maior área do centro de pressão, e consequentemente maior medo de cair (Niederer et al., 2013).

A redução da velocidade da marcha não reflete somente uma redução da atividade motora, mas também é um indicador de estimativas de sobrevivência (Studenski et al., 2011).

O tamanho das mamas parece ter influência nas variáveis cinemáticas da marcha. Mulheres apresentaram menor ângulo de inclinação do tronco e menor anteversão pélvica após cirurgia de mamoplastia redutora (Sahin et al.,2013).

Hojan et al, (2013) sugerem influência positiva do uso da prótese mamária externa no estado funcional das mulheres após mastectomia unilateral, já que parâmetros espaço temporais da marcha foram afetados positivamente com o uso da prótese mamária externa, sendo mais próximos do grupo de mulheres saudáveis com a mesma idade, isto ocorre principalmente em mulheres mais jovens. Não foram encontradas diferenças significativas na marcha com e sem o uso da prótese mamária externa, possivelmente pela falta de adaptação ao uso da mesma.

Nosso estudo expande a investigação da marcha em pacientes com câncer de mama, apresentando uma visão mais detalhada da complexidade das variáveis 
pesquisadas na marcha, sendo levadas em consideração as alterações de tronco e membros superiores que são encontradas na posição estática para uma atividade funcional e dinâmica como a marcha, sendo esta a finalidade da mensuração da movimentação dos ombros e tronco nos diferentes planos.

No contato inicial e transferência de carga do ciclo da marcha, o membro superior contralateral ao membro inferior nestas fases, está à frente do corpo, e deve atingir seu máximo de grau de flexão de ombro (Park et al., 2008). O membro superior homolateral à cirurgia de mastectomia, demonstrou menor eficiência do movimento de flexão neste momento da marcha, com amplitude de movimento do ombro significativamente menor que o grupo controle, prejudicando assim também os outros parâmetros da marcha.

O movimento do tronco, no início do apoio médio até a fase de pé-balanço, na marcha normal, deveria atingir o máximo deslocamento para o lado apoiado. A cirurgia de mastectmoia altera a cinemática do tronco superior, nos movimentos isolados e no alinhamento da coluna na postura (Crosbie el al., 2010. Barbosa et al., 2013). Na marcha, parece que esta alteração também afeta sua cinemática, já que os resultados mostraram menor deslocamento do tronco para o lado homolateral a cirurgia.

A influência do tratamento cirúrgico do câncer de mama no controle postural estático e dinâmico deve ser considerada no processo de reabilitação de mulheres mastectomizadas, inclusive para o emprego adequado da prótese externa. Os efeitos desta na postura após uso prolongado deve ser melhor investigada, sendo esta uma sugestão para estudo complementar. 
Conclusáa

44 


\section{CONCLUSÃO}

Os resultados obtidos através deste estudo, permitem concluir que mulheres com mastectomia unilateral apresentaram:

- Diferença significativa no equilíbrio estático, com aumento da instabilidade;

- Menor oscilação do ombro homolateral à cirurgia, na movimentação de flexão/extensão e abdução/adução durante a marcha;

- Diferenças significativas na oscilação do ombro homolateral à cirurgia, nos planos sagital e transverso durante o ciclo da marcha, comparado ao ombro de mulheres sem a doença;

- Alteração significativa na oscilação médio-lateral do tronco durante o ciclo da marcha quando comparadas a mulheres sem a doença.

- A prótese mamária externa não influenciou o equilíbrio estático e os parâmetros espaço-temporais da marcha. 
Oreferéncias 


\section{REFERÊNCIAS}

Aitken DR. Complications Associated with Mastectomy. Surg Clinics of North America. 1983;63:1331-52.

Andersen L, Højris I, Erlandsen M, Andersen J. Treatment of breast-cancer-related lymphedema with or without manual lymphatic drainage. Acta Oncol. 2000;39(3):399405.

Anker LC, Weerdesteyn V, van Nes IJ, Nienhuis B, Straatman H, Geurts AC.The relation between postural stability and weight distribution in healthy subjects. Gait Posture. 2008;27(3):471-477.

Araújo CDM, Gomes HC, Veiga DF, Hochmam B, Fernandes PM, Novo NF et al. Influência da Hipertrofia Mamária na Capacidade Funcional das Mulheres. Rev Bras Reumatol. 2007;47(2):91-96

Barbosa AF, Lavoura PH, Boffino CC, Siqueira CM, Costa MP, Lima Junior JE et al. The impact of surgical breast reduction on the postural control of women with breast hypertrophy. Aesthetic Plast Surg. 2013;37(2):321-326.

Barbosa AF, Raggi GC, Sá CSC, Costa MP, Lima JEJ, Tanaka C. Postural control in women with breast hypertrophy. Clinics. 2012;67(7):757-760. I

Bankoff ADP, Salve MGC. Postura corporal: fatores biológicos da postura ereta: causas e consequências. Brasília, DF: Ministério da Saúde/Ministério da Educação e do Desporto; 1996.

Bossombra K, Ashicaga T, O’Brien PJ, Nelson L, Skelly J. Swelling, numbness, pain, and their relationship to arm function among breast cancer survivors: a disablement process model perspective. Breast J. 2002;8(6):338-48. 
Borghesan DH, Gravena AA, Lopes TC, Brischiliari SC, Demitto Mde O, Agnolo CM et al. Variables that Affect the Satisfaction of Brazilian Women with External Breast Prostheses after Mastectomy. Asian Pac J Cancer Prev. 2014; 15(22):9631-4.

Braccialli LM, Vilarta R. Postura corporal: reflexões teóricas. Rev Fis Mov. 2001; 14(1):65-71.

BRASIL, MINISTÉRIO DA SAÚDE. INSTITUTO NACIONAL DO CÂNCER. Incidência de câncer no Brasil. Disponível em: <http://www2.inca.gov.br/wps/wcm/connect/tiposde cancer/site/home/mama>. Acesso em: 05 set. 2013.

Buckley MM, Goa KL. Tamoxifen: A reappraisal of its pharmacodynamic and pharmacokinetic properties and therapeutic use. Drugs. 1989;37(4):451-490.

Camargo MC, Marx AG. Reabilitação física no câncer de mama. São Paulo: Roca, 2000 .

Carmo AA, Kleiner AFR, Lobo da Costa PH, Barros RML. Three-dimensional kinematic analysis of upper and lower limb motion during gait of post-stroke patients. Braz J Medl Biol Res. 2012;45(6):537-545.

Ciesla S, Polom K. The effect of immediate breast reconstruction with Becker-25 prosthesis on the preservation of proper body posture in patients after mastectomy. Eur J Surg Oncol. 2010;36(7):625-31.

Cheville AL, Tcgou J. Barriers to rehabilitation following surgery for primary breast cancer. J Surg Oncol. 2007;95:409-18.

Chiari L, Rocchi L, Cappello A. Stabilometric parameters are affected by anthropometry and foot placement. Clin Biomech. 2002;17:666-77. 
Crosbie J, Kilbreath SL, Dylke E, Refshauge KM, Nilcholson L, Beith JM, et al. Effects of mastectomy on shoulder and spinal kinematics during bilateral upper-limb movement. Phys Ther. 2010;90:679-692.

Danis CG, Krebs DE, Gill-Body KM, Sahrmann S. Relationship between standing posture and stability. Phys Ther. 1998;78(5):501-519.

DISABILITIES OF THE ARM, SHOULDER, AND HAND QUESTIONAIRE (DASH).

Disponível

em:

http://www.dash.iwh.on.ca/system/files/translations/DASH_Portuguese_Brazil.pdf.

Acesso em: 25 Fev 2013.

Dye DC, Eakman AM, Bolton KM. Assessing the validity of the dynamic gait index in a balance disorders clinic: an application of Rasch analysis. Phys Ther. 2013;93(6):809-18.

Eke-Okoro ST, Gregoric M, Larsson LE. Alterations in gait resulting from deliberate changes of arm-swing amplitude and phase. Clin Biomech. 1997;12:516-521.

Ferlay J, Shin HR, Bray F, Forman D, Mathers CD, Parkin D. GLOBOCAN.2008, Cancer Incidence and Mortality Worldwide: IARC CancerBase. No. 10. Lyon, France: International Agency for Research on Cancer; Year.

Fernandes PM, Neto MS, Veiga DF, Abla LEF, Mundim CDA, Juliano Y et al. Back Pain: an assessement in breast hypertrophy patients. Acta Orto Bras. 2007;15(4):227230.

Fernández-Lao C, Cantarero-Villanueva I, Fernández-de-Las-Peñas C, Del Moral-Ávila R, Castro-Sánchez AM, Arroyo-Morales M. Effectiveness of a multidimensional physical therapy program on pain, pressure hypersensitivity, and trigger points in breast cancer survivors: a randomized controlled clinical trial. Clin J Pain. 2012;28(2):113-21. 
Filler K, Kelly DL, Lyon D. Fall risk in adult inpatients with leukemia undergoing induction chemotherapy. Clin J Oncol Nurs. 2011;15(4):369-70.

Fitch MI, McAndrew A, Harris A, Anderson J, Kubon T, McClennen J. Perspectives of women about external breast prostheses. Can Oncol Nurs J. 2012;22(3):162-74.

Flores AM, Dwyer K Shoulder impairment before breast cancer surgery. J Womens Health Phys Therap. 2014;38(3):118-124.

Genthon N, Rougier P. Influence of an asymmetrical body weight distribution on the control of undisturbed upright stance. J Biomech. 2005;38: 2037-2049.

Gouveia PF, Gonzalez EO, Grer PA, Fernandes CA, Lima MC. Avaliação da amplitude de movimento e força da cintura escapular em pacientes de pós-operatório tardio de mastectomia radical modificada. Fisioter Pesqui. 2008;15(2):172-6.

Gur G, Dilek B, Ayhan C, Simsek E, Aras O, Aksoy S et al. Effect of a spinal brace on postural control in different sensory conditions in adolescent idiopathic scoliosis: a preliminary analysis. Gait Posture. 2014; 41(1):93-9.

Haagensen CD. A technique for radical mastectomy. Surg. 1946;19:100-31.

Halsted CP, Benson JR, Jatoi I. A historical account of breast cancer surgery: beware of local recurrence but be not radical. Future Oncol. 2014;10(9):1649-57.

Harrington S, Michener LA, Kendig T, Miale S, George SZ. Patient-reported upper extremity outcome measures used in breast cancer survivors: a systematic review. Arch Phys Med Rehabil. 2014; 95(1):153-62.

Hile ES, Fitzgerald GK, Studenski SA. Persistent Mobility Disability After Neurotoxic Chemotherapy. Phys Ther. 2010; 90(11):1649-1657.

Hof AL, Gazendam MGJ, Sinke WE. The condition for dynamic stability. J Biomech. 2005;38:1-8. 
Hojris I, Andersen J, Overgaard M, Overgaard J. Late treatment-related morbidity in breast cancer patients randomizes to postmastectomy radiotherapy and systemic treatment versus systemic treatment alone. Acta Oncologica. 2000; 39(3):355-372.

[INCA].,M.D.S.I.N D. C. Estimativas de incidência e mortalidade por câncer de mama no brasil., Instituto Nacional do Câncer [INCA]. 2012. Acesso em 16/outubro.

[INCA].,M.D.S.I.N.D.C. Controle do Câncer de Mama. Documento de Consenso.2004.

INTERNACIONAL PHYSICAL QUENTIONNAIRE. Disponível em: <http://www.ipaq.ki.se/dloads/IPAQ_SHORT_LAST_7_SELF_ADM-revised_8-2302.pdf>. Acesso em: 04 out 2004.

Jaeheung P. Synthesis of natural arm swing motion in human bipedal walking. J Biomech. 2008;41(7):1417-1426.

Jemal DVM, Bray F, Center MM, Ferlay ME, Ward E, Forman DA et al. Global cancer statistics. CA Cancer J Clin. 2011; 61(2):69-90.

Jun Ling C, Abbot C, Skubic M, Keller J. Investigation of Gait Features for Stability and Risk Identification in Elders. 31st Annual International Conference of the IEEE EMBS Minneapolis, Minnesota, USA, September 2-6, 2009.

Justus DO, Leslie AF, Claire TF. Effects of aging and arm swing on the metabolic cost of stability in human walking. J Biomech. 2008; 41(16):3303-3308.

Kapandji AI. Fisiologia Articular, volume 1: membros superiores. 2000. São Paulo. Ed Panamericana, 5 ed, 2000.

Kaufmann M, von Minckwitz G, Bear HD, Buzdar A, McGale P, Bonnefoi H et al. Recommendations from an international expert panel on the use of neoadjuvant 
(primary) systemic treatment of operable breast cancer: new perspectives. Ann Oncol. 2007; 18(12):1927-34.

Kavanagh JJ, Barrett RS, Morrisson S. Upper body accelerations during walking in healthy young and elderly men. Gait Posture. 2004; 20(3) 291-298.

Kim JW, Yoonj Y, Kang MH. Selective activation of the infraspinatus during various shoulder external rotation exercise. J Phys Ther Sci. 2012; (24):581-584.

Kurban IZ, Lima WC. Tratamento fisioterapeutico tardio em mastectomizadas. Rev Fisiot Mov. 2003;(16):29-3.

Ladeira SMG. Tratamento sistêmico do câncer de mama. In: FRANCO, J. M. Mastologia: formação do especialista. São Paulo: Atheneu, 1997;229-237.

Lapid O, de Groof EJ, Corion LU, Smeulders MJ, van der Horst CM. The effect of breast hypertrophy on patient posture. Arch Plast Surg. 2013; 40(5):559-63.

Lauridsen MC, Christiansen P, Hessov I. The effect of physiotherapy on shoulder function in patients surgically treated for breast cancer: a randomized study. Acta Oncol. 2005; 44(5):449-57.

Leardini A, Biagi F, Merlo A, Belvedere C, Benedetti MG. Multi-segment trunk kinematics during locomotion and elementary exercises. Clin Biomech. 2011; 26(6):562-571.

Lyman GH, Giuliano AE, Somerfield MR, Benson AB 3rd, Bodurka DC, Burstein HJ et al. American Society of Clinical Oncology guideline recommendations for sentinel lymph node biopsy in early-stage breast cancer. J Clin Oncol. 2005; 23(30):7703-20.

Madden JL, Kandalafft S, Bourque RA. Modified radical mastetomy. Ann Surg. 1972; 175(5):624-34. 
Magee DJ. Avaliação Musculoesquelética. 4a Edição. São Paulo: Manole; 2005.

Makluf ASD, Dias RC, Barra AA. Avaliação da qualidade de vida em mulheres com câncer da mama. Rev Bras Cancerol. 2006;52(1):49-58.

Melo MSI, Maia JN, Silva DAL, Carvalho C. Avaliação Postural em Pacientes Submetidas à Mastectomia Radical Modificada por meio da Fotogrametria Computadorizada. Rev Bras Canc. 2011;57(1):39-48.

Milosevic M, McConville KM, Masani K. Arm movement improves performance in clinical balance and mobility test. Gait Posture. 2011 Mar;33(3):507-9.

Mochizuki L. Amadio CA. Aspectos biomecânicos da postura ereta: a relação entre o centro de massa e o centro de pressão. Revista Portuguesa de Ciências do Desporto. $2003 ; 3: 77-83$.

Montezuma T. Guirro ECO. Vaz MMOLL. Vernal S. Changes in postural control in mastectomized women. Journal of Cancer Therapy. 2014; 5:493-499

Orfalle AG, Araújo PMP, Ferraz MB, Natour J. Translation into brazzilian portuguese, cultural adaptation and evaluation of the reliability of the disabilities of the arm, shoulder and hand questionnaire. Braz J Med Biol Res. 2005;(38):293-302.

Ortega JD, Fehlman LA, Farley CT. Effects of aging and arm swing on the metabolic cost of stability in human walking. J Biomech. 2008 Dec 5;41(16):3303-8

Park J. Synthesis of natural arm swing motion in human bipedal walking. J Biomech. 2008;41(7): 1417-1426.

Patey DH, Dyson WH. The prognosis of carcinoma of the breast in relation to the type of operation performed. Br J Cancer. 1948;2(1):7-13. 
Pautex S, Herrmann FR, Zulian GB. Factors associated with falls in patients with cancer hospitalized for palliative care. J Palliat Med. 2008;11:878-84.

Pereira TB, Bergmann A, Ribeiro ACP, Silva JG, Dias R, Ribeiro MJP et al. Padrão da atividade mioelétrica dos músculos da cintura escapular após linfadenectomia axilar no câncer de mama. Rev Bras Ginecol Obstet. 2009;31(5):224-9.

Riad J, Coleman S, Lundh D, Brosto E. Arm posture score and arm movement during walking: A comprehensive assessment in spastic hemiplegic cerebral palsy. Gait Posture. 2011;33(1):48-53.

Rietman JS, Dijkstra PU, Hoekstra HJ, Eisma WH, Szabo BG, Groothoff JW et al. Late morbidity after treatment of breast cancer in relation to daily activities and quality of life:a systematic review. Eur J Surg Oncol. 2003;29(3):229-38.

Roos PE, McGuigan MP, Kerwin DG, Trewartha G. The role of arm movement in early trip recovery in younger and older adults. Gait Posture. 2008;27(2):352-6.

Rose J, Gamble JG. Marcha Humana. 2aed. São Paulo: Premier, 1993.

Rostkowasca E, Bak M, Samborski W. Body posture in women after mastectomy and its changes as a result of rehabilitation. Adv Med Sci. 2006;51:287-97.

SacchiniI V, Luini A, Tana S, Lozza L, Galimberti V, Merson M et al. Quantitative and qualitative cosmetic evaluation after conservative treatment for breast cancer. Eur $\mathbf{J}$ Cancer. 1991;27(11):1395-1400.

Samphao S, Eremin JM, El-Sheemy M, Eremin O. Management of the axilla in women with breast cancer: current clinical practice and a new selective targeted approach. Ann Surg Oncol. 2008;15(5):1282-96. 
Sancho A, Carrera S, Arietaleanizbeascoa M, Arce V, Gallastegui N, Giné March A et al. Supervised physical exercise to improve the quality of life of cancer patients: the EFICANCER randomised controlled trial. BMC Cancer. 2015; 6;15(1):40.

Sander AP, Hajer NM, Hemenway K, Miller AC. Upper-extremity volume measurements in women with lymphedema: a comparison of measurements obtained via water displacement with geometrically determined volume. Phys Ther. 2002; 82(12):1201-12.

Schmitz KH, Courneya KS, Matthews C, Demark-Wahnefried W, Galvão DA, Pinto $\mathrm{BM}$, et al. American college of sports medicine roundtable on exercise guidelines for cancer survivors. Med Sci Sports Exerc. 2010;42(7):1409

Shamley D, Lascurain-aguirrebeña I, Oskrochi R, Srinaganathan R. Shoulder morbidity after treatment for breast cancer is bilateral and greater after mastectomy. Rev Acta Oncol. 2012;51(8):1045-1053.

Shamley D, Srinaganathan R, Oskrochi R, Lascurain-Aguirrebeña I, SugdenE. Three dimensional scapulothoracic motion following treatment for breast cancer. Breast cancer Res Treat. 2009;118(2):315-22.

Shamley D, Srinanaganathan R, Weatherall R, Oskrochi R, Watson M, Ostlere S et al. Changes in shoulder muscle size and activity following treatment for breast câncer. Breast Cancer Res Treat. 2007;106(1):19-27.

Syszewka M, Graff K, Alinowska M, Szcerbik E, Domaniecki J. Influence of the structural deformity of the spine on the gait pathology in scoliotic patients. Gait Posture. 2012;35(2):209-213.

Teo I, Novy DM, Change DW, Cox MG, Fingeret MC. Examining pain, body image, and depressive symptoms in patients with lymphedema secondary to breast cancer. Psychooncology. 2015. 
Umberger BR. Effects of suppressing arm swing on kinematics, kinetics, and energetics of human walking. J Biomech. 2008 Aug 7;41(11):2575-8

van Abellan Kan G, Rolland Y, Andrieu S, Bauer J, Beauchet O, Bonnefoy M et al. Gait speed at usual pace as a predictor of adverse outcomes in community-dwelling older people an International Academy on Nutrition and Aging (IANA) Task Force. J Nutr Health Aging. 2009;13(10):881-9.

Veronese, U, Cascinelle, N, Mariani, L, Greco M, Saccozzi R, Luini A et al. Twentyyear follow-up of a randomized study comparing breast-conserving surgery with radical mastectomy for early breast cancer. N Engl J Med. 2002;347:1227-1232.

Wampler MA, Topp KS, Miaskowski C, Byl NN, Rugo HS, Hamel K. Quantitative and Clinical Description of Postural Instability in Women With Breast Cancer Treated With Taxane Chemotherapy. Arch Phys Med Rehabil. 2007;88(8):1002-1008.

Winter DA. Human balance and posture control during standing and walking. Gait Posture. 1995;3(4):193-214. 
ANEXO A 
Oficio $\mathrm{n}^{\circ} 3170 / 2013$

CEP/MGV

Prezadas Senhoras,

O trabalho intitulado "INFLUÊNCIA DA MASTECTOMIA UNILATERAL NO EQUILÍBRIO ESTÁTICO E NA MARCHA" - versão 3, de 12/08/2013, foi analisado pelo Comitê de Ética em Pesquisa, em sua $372^{\text {a }}$ Reunião Ordinária realizada em 26/08/2013 e enquadrado na categoria: APROVADO, bem como o Termo de Consentimento Livre e Esclarecido versão 3, de 12/08/2013, de acordo com o Processo HCRP n ${ }^{\circ} 8341 / 2013$.

De acordo com Carta Circular $n^{\circ}$ 003/2011/CONEP/CNS, datada de 21/03/2011, o sujeito de pesquisa ou seu representante, quando for o caso, deverá rubricar todas as folhas do Termo de Consentimento Livre e Esclarecido - TCLE - apondo sua assinatura na última do referido Termo; o pesquisador responsável deverá da mesma forma, rubricar todas as folhas do Termo de Consentimento Livre e Esclarecido - TCLE - apondo sua assinatura na última página do referido Termo.

Este Comitê seque integralmente a Conferência Internacional de Harmonização de Boas Práticas Clínicas (IGH-GCP), bem como a Resolução $n^{o}$ $466 / 12 \mathrm{CNS} / \mathrm{MS}$. Relatório Parcial e o Relatório Final da pesquisa.

Lembramos que devem ser apresentados a este CEP, o

Atenciosamente.

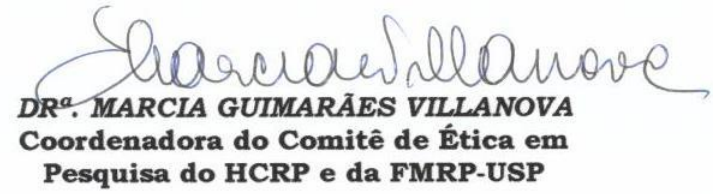

Ilustríssimas Senhoras

PROF $^{\text {a }}$.DR ${ }^{\text {a }}$.ELAINE CALDEIRA DE OLIVEIRA GUIRRO(Orientadora)

CARLA SILVA PEREZ

Depto. de Biomecânica, Medicina e Reabilitação do Aparelho Locomotor

Campus Universitário - Monte Alegre
$\begin{array}{r}\text { Comitê de Ética em Pesquisa HCRP e FMRP-USP } \\ \text { 14048-900 Ribeirão Preto SP }\end{array}$
WWA-00002733;IRB-00002186 e Registro PB/CONEP n 5440
(16) $3602-2228$
cep@hcrp.usp.br

\section{ANEXO B}


Disfunções do braço, ombro e mão

\section{Instruções}

Esse questionário é sobre seus sintomas, assim como suas habilidades para fazer certas atividades.

Por favor, responda todas as questões baseando-se na sua condição na semana passada.

Se você não teve a oportunidade de fazer uma das atividades na semana passada, por favor, tente estimar qual resposta seria a mais correta.

Não importa qual mão ou braço você usa para fazer a atividade; por favor, responda baseando-se na sua habilidade independentemente da forma como você faz a tarefa.

Â@ IWH 2003. All rights reserved. 


\section{Disfunções do braço, ombro e mão}

Meça a sua habilidade de fazer as seguintes atividades na semana passada circulando a resposta apropriada abaixo:

\begin{tabular}{|c|c|c|c|c|c|}
\hline & $\begin{array}{l}\text { Não houve } \\
\text { dificuldade }\end{array}$ & $\begin{array}{l}\text { Houve pouca } \\
\text { dificuldade }\end{array}$ & $\begin{array}{l}\text { Houve } \\
\text { dificuldade } \\
\text { média } \\
\end{array}$ & \begin{tabular}{|l|} 
Houve \\
muita \\
dificuldade \\
\end{tabular} & \begin{tabular}{|l|}
$\begin{array}{l}\text { Não } \\
\text { conseguiu } \\
\text { fazer }\end{array}$ \\
\end{tabular} \\
\hline $\begin{array}{l}\text { 1. Abrir um vidro novo ou com a tampa } \\
\text { muito apertada. }\end{array}$ & 1 & 2 & 3 & 4 & 5 \\
\hline \begin{tabular}{l|l} 
2. Escrever. & 1 \\
\end{tabular} & 1 & 2 & 3 & 4 & 5 \\
\hline 3. Virar uma chave. & 1 & 2 & 3 & 4 & 5 \\
\hline 4. Preparar uma refeição. & 1 & 2 & 3 & 4 & 5 \\
\hline 5. Abrir uma porta pesada. & 1 & 2 & 3 & 4 & 5 \\
\hline $\begin{array}{l}\text { 6. Colocar algo em uma prateleira } \\
\text { acima de sua cabeça. }\end{array}$ & 1 & 2 & 3 & 4 & 5 \\
\hline $\begin{array}{l}\text { 7. Fazer tarefas domésticas pesadas } \\
\text { (por exemplo: lavar paredes, lavar } \\
\text { o chão). }\end{array}$ & 1 & 2 & 3 & 4 & 5 \\
\hline 8. Fazer trabalho de jardinagem. & 1 & 2 & 3 & 4 & 5 \\
\hline 9. Arrumar a cama. & 1 & 2 & 3 & 4 & 5 \\
\hline $\begin{array}{l}\text { 10. Carregar uma sacola ou uma } \\
\text { maleta. }\end{array}$ & 1 & 2 & 3 & 4 & 5 \\
\hline $\begin{array}{l}\text { 11. Carregar um objeto pesado (mais } \\
\text { de } 5 \mathrm{~kg} \text { ). }\end{array}$ & 1 & 2 & 3 & 4 & 5 \\
\hline $\begin{array}{l}\text { 12. Trocar uma lâmpada acima da } \\
\text { cabeça. }\end{array}$ & 1 & 2 & 3 & 4 & 5 \\
\hline 13. Lavar ou secar o cabelo. & 1 & 2 & 3 & 4 & 5 \\
\hline 14. Lavar suas costas. & 1 & 2 & 3 & 4 & 5 \\
\hline 15. Vestir uma blusa fechada. & 1 & 2 & 3 & 4 & 5 \\
\hline $\begin{array}{l}\text { 16. Usar uma faca para cortar } \\
\text { alimentos. }\end{array}$ & 1 & 2 & 3 & 4 & 5 \\
\hline $\begin{array}{l}\text { Atividades recreativas que } \\
\text { exigem pouco esforço (por } \\
\text { exemplo: jogar cartas, tricotar). }\end{array}$ & & 2 & 3 & 4 & 5 \\
\hline $\begin{array}{l}\text { Atividades recreativas } \\
\text { exigem força ou impacto nos } \\
\text { braços, ombros ou mãos (por } \\
\text { exemplo: jogar vôlei, martelar). }\end{array}$ & & 2 & 3 & 4 & 5 \\
\hline $\begin{array}{l}\text { 19. Atividades recreativas nas quais } \\
\text { você move seu braço livremente } \\
\text { (como pescar, jogar peteca). }\end{array}$ & & 2 & 3 & 4 & 5 \\
\hline $\begin{array}{l}\text { 20. Transportar-se de um lugar a } \\
\text { outro (ir de um lugar a outro). }\end{array}$ & 1 & 2 & 3 & 4 & 5 \\
\hline
\end{tabular}


Â@ IWH 2003. All rights reserved.

\section{Disfunções do braço, ombro e mão}

\begin{tabular}{|l|l|l|l|l|l|}
\cline { 2 - 5 } \multicolumn{1}{l|}{} & Não afetou & Afetou pouco & $\begin{array}{l}\text { Afetou } \\
\text { Mediana } \\
\text { mente }\end{array}$ & Afetou muito & $\begin{array}{l}\text { Afetou } \\
\text { Extrema } \\
\text { Mente }\end{array}$ \\
\hline $\begin{array}{l}\text { 22. Na semana passada, em } \\
\text { que ponto o seu problema } \\
\text { com braço, ombro ou mão } \\
\text { afetaram suas atividades } \\
\text { normais com família, amigos, } \\
\text { vizinhos ou colegas? }\end{array}$ & 1 & 2 & 3 & 4 & 5 \\
\hline $\begin{array}{l}\text { 23. Durante a semana } \\
\text { passada, o seu trabalho ou } \\
\text { atividades diárias normais } \\
\text { foram limitadas devido ao seu } \\
\text { problema com braço, ombro } \\
\text { ou mão? }\end{array}$ & 1 & Limitou pouco & $\begin{array}{l}\text { Limitou } \\
\text { medianamente }\end{array}$ & Limitou muito & $\begin{array}{l}\text { Não } \\
\text { conseguiu } \\
\text { fazer }\end{array}$ \\
\hline
\end{tabular}

\begin{tabular}{|c|c|c|c|c|c|}
\hline $\begin{array}{l}\text { Meça a gravidade dos } \\
\text { seguintes sintomas na semana } \\
\text { passada. }\end{array}$ & Nenhuma & Pouca & Mediana & Muita & Extrema \\
\hline $\begin{array}{l}\text { 24. Dor no braço, ombro ou } \\
\text { mão. }\end{array}$ & 1 & 2 & 3 & 4 & 5 \\
\hline $\begin{array}{l}\text { 25. Dor no braço, ombro ou } \\
\text { mão quando você fazia } \\
\text { atividades especificas. }\end{array}$ & 1 & 2 & 3 & 4 & 5 \\
\hline $\begin{array}{l}\text { 26. Desconforto na pele } \\
\text { (alfinetadas) no braço, ombro } \\
\text { ou mão. }\end{array}$ & 1 & 2 & 3 & 4 & 5 \\
\hline $\begin{array}{l}\text { 27. Fraqueza no braço, ombro } \\
\text { ou mão. }\end{array}$ & 1 & 2 & 3 & 4 & 5 \\
\hline $\begin{array}{l}28 . \quad \text { Dificuldade em mover } \\
\text { braço, ombro ou mão. }\end{array}$ & 1 & 2 & 3 & 4 & 5 \\
\hline & $\begin{array}{l}\text { Não houve } \\
\text { dificuldade }\end{array}$ & $\begin{array}{l}\text { Pouca } \\
\text { dificuldade }\end{array}$ & $\begin{array}{l}\text { Média } \\
\text { dificuldade }\end{array}$ & $\begin{array}{l}\text { Muita } \\
\text { dificuldade }\end{array}$ & $\begin{array}{ll}\text { Tão } & \text { difícil } \\
\text { que } & \text { você } \\
\text { não } & \text { pode }\end{array}$ \\
\hline
\end{tabular}




\begin{tabular}{|c|c|c|c|c|c|}
\hline & & & & & dormir \\
\hline \multirow{2}{*}{$\begin{array}{l}\text { 29. Durante a semana } \\
\text { passada, qual a dificuldade } \\
\text { você teve para dormir por } \\
\text { causa da dor no seu braço, } \\
\text { ombro ou mão? }\end{array}$} & 1 & 2 & 3 & 4 & 5 \\
\hline & $\begin{array}{l}\text { Discordo } \\
\text { totalmente }\end{array}$ & Discordo & $\begin{array}{l}\text { Não concordo } \\
\text { nem discordo }\end{array}$ & Concordo & $\begin{array}{l}\text { Concordo } \\
\text { totalmente }\end{array}$ \\
\hline $\begin{array}{l}\text { 30. Eu me sinto menos capaz, } \\
\text { menos confiante e menos útil } \\
\text { por causa do meu problema } \\
\text { com braço, ombro ou mão. }\end{array}$ & 1 & 2 & 3 & 4 & 5 \\
\hline
\end{tabular}

Â@ IWH 2003. All rights reserved.

\section{Disfunções do braço, ombro e mão}

As questões que seguem são a respeito do impacto causado no braço, ombro ou mão quando você toca um instrumento musical, pratica esporte ou ambos.

Se você toca mais de um instrumento, pratica mais de um esporte ou ambos, por favor, responda com relação ao que é mais importante para você.

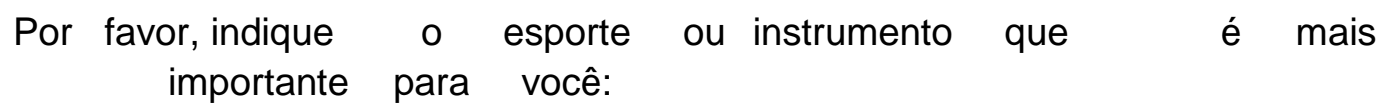

Eu não toco instrumentos ou pratico esportes (você pode pular essa parte)

Por favor circule o número que melhor descreve sua habilidade física na semana passada. Você teve alguma dificuldade para:

\begin{tabular}{|l|l|l|l|l|l|}
\cline { 2 - 6 } \multicolumn{1}{l|}{} & Fácil & Pouco difícil & $\begin{array}{l}\text { Dificuldade } \\
\text { média }\end{array}$ & Muito difícil & $\begin{array}{l}\text { Não } \\
\text { conseguiu } \\
\text { fazer }\end{array}$ \\
\hline $\begin{array}{l}\text { 1. uso de sua técnica habitual para tocar } \\
\text { instrumento ou praticar esporte? }\end{array}$ & 1 & 2 & 3 & 5 & 5 \\
\hline $\begin{array}{l}\text { 2. tocar o instrumento ou praticar o } \\
\text { esporte por causa de dor no braço, } \\
\text { ombro ou mão? }\end{array}$ & 1 & 2 & 3 & 4 & 5 \\
\hline $\begin{array}{l}\text { 3. tocar seu instrumento ou praticar o } \\
\text { esporte tão bem quanto você gostaria? }\end{array}$ & 1 & 2 & 3 & 4 & 5 \\
\hline
\end{tabular}




\begin{tabular}{|l|l|l|l|l|l|}
\hline $\begin{array}{l}\text { 4. usar a mesma quantidade de tempo } \\
\text { tocando seu instrumento ou praticando o } \\
\text { esporte? }\end{array}$ & 1 & 2 & 3 & 4 & 5 \\
\hline
\end{tabular}

As questões seguintes são sobre o impacto do seu problema no braço, ombro ou mão em sua habilidade de trabalhar (incluindo tarefas domésticas se este é seu principal trabalho)

Por favor, indique qual é o seu trabalho:

trabalho (você pode pular essa parte)

Eu não

Por favor, circule o número que melhor descreve sua habilidade física na semana passada. Você teve alguma dificuldade para:

\begin{tabular}{|l|l|l|l|l|l|}
\cline { 2 - 6 } \multicolumn{1}{l|}{} & Fácil & Pouco difícil & $\begin{array}{l}\text { Dificuldade } \\
\text { média }\end{array}$ & Muito difícil & $\begin{array}{l}\text { Não } \\
\text { conseguiu } \\
\text { fazer }\end{array}$ \\
\hline $\begin{array}{l}\text { 1. uso de sua técnica habitual para seu } \\
\text { trabalho? }\end{array}$ & 1 & 2 & 3 & 4 & 5 \\
\hline $\begin{array}{l}\text { 2. fazer seu trabalho usual por causa de } \\
\text { dor em seu braço, ombro ou mão? }\end{array}$ & 1 & 2 & 3 & 4 & 5 \\
\hline $\begin{array}{l}\text { 3. fazer seu trabalho tão bem quanto } \\
\text { você gostaria? }\end{array}$ & 1 & 2 & 3 & 4 & 5 \\
\hline $\begin{array}{l}\text { 4. usar a mesma quantidade de tempo } \\
\text { fazendo seu trabalho? }\end{array}$ & 1 & 2 & 3 & 4 & 5 \\
\hline
\end{tabular}

Â@ IWH 2003. All rights reserved. 


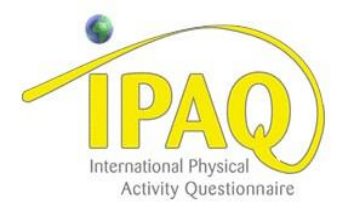

QUESTIONÁRIO INTERNACIONAL DE ATIVIDADE FÍSICA -

VERSÃO CURTA -

Nome:

Data:

1

I

Idade :

Sexo: $F($ ) $M($ )

Nós estamos interessados em saber que tipos de atividade física as pessoas fazem como parte do seu dia a dia. Este projeto faz parte de um grande estudo que está sendo feito em diferentes países ao redor do mundo. Suas respostas nos ajudarão a entender que tão ativos nós somos em relação à pessoas de outros países. As perguntas estão relacionadas ao tempo que você gasta fazendo atividade física na ÚLTIMA semana. As perguntas incluem as atividades que você faz no trabalho, para ir de um lugar a outro, por lazer, por esporte, por exercício ou como parte das suas atividades em casa ou no jardim. Suas respostas são MUITO importantes. Por favor responda cada questão mesmo que considere que não seja ativo. Obrigado pela sua participação!

Para responder as questões lembre que:

atividades físicas VIGOROSAS são aquelas que precisam de um grande esforço físico e que fazem respirar MUITO mais forte que o normal

atividades físicas MODERADAS são aquelas que precisam de algum esforço físico e que fazem respirar UM POUCO mais forte que o normal

Para responder as perguntas pense somente nas atividades que você realiza por pelo menos 10 minutos contínuos de cada vez.

1a Em quantos dias da última semana você CAMINHOU por pelo menos 10 minutos contínuos em casa ou no trabalho, como forma de transporte para ir de um lugar para outro, por lazer, por prazer ou como forma de exercício?

dias por SEMANA ( ) Nenhum

1b Nos dias em que você caminhou por pelo menos 10 minutos contínuos quanto tempo no total você gastou caminhando por dia? 
horas: Minutos:

2a. Em quantos dias da última semana, você realizou atividades MODERADAS por pelo menos 10 minutos contínuos, como por exemplo pedalar leve na bicicleta, nadar, dançar, fazer ginástica aeróbica leve, jogar vôlei recreativo, carregar pesos leves, fazer serviços domésticos na casa, no quintal ou no jardim como varrer, aspirar, cuidar do jardim, ou qualquer atividade que fez aumentar moderadamente sua respiração ou batimentos do coração (POR FAVOR NÃO

INCLUA CAMINHADA)

dias por SEMANA

( ) Nenhum

2b. Nos dias em que você fez essas atividades moderadas por pelo menos 10 minutos contínuos, quanto tempo no total você gastou fazendo essas atividades por dia?

horas: Minutos:

3a Em quantos dias da última semana, você realizou atividades VIGOROSAS por pelo menos 10 minutos contínuos, como por exemplo correr, fazer ginástica aeróbica, jogar futebol, pedalar rápido na bicicleta, jogar basquete, fazer serviços domésticos pesados em casa, no quintal ou cavoucar no jardim, carregar pesos elevados ou qualquer atividade que fez aumentar MUITO sua respiração ou batimentos do coração.

dias por SEMANA

( ) Nenhum

3b Nos dias em que você fez essas atividades vigorosas por pelo menos 10 minutos contínuos quanto tempo no total você gastou fazendo essas atividades por dia?

horas: Minutos:

Estas últimas questões são sobre o tempo que você permanece sentado todo dia, no trabalho, na escola ou faculdade, em casa e durante seu tempo livre. Isto inclui o tempo sentado estudando, sentado enquanto descansa, fazendo 
lição de casa visitando um amigo, lendo, sentado ou deitado assistindo TV. Não inclua o tempo gasto sentando durante o transporte em ônibus, trem, metrô ou carro.

4a. Quanto tempo no total você gasta sentado durante um dia de semana? horas __ minutos

4b. Quanto tempo no total você gasta sentado durante em um dia de final de semana?

horas __ minutos 


\title{
APÊNDICE 1
}

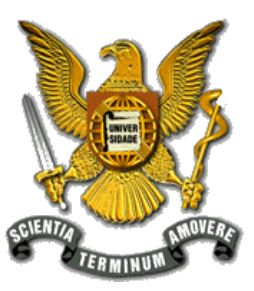

\section{UNIVERSIDADE DE SÃO PAULO FACULDADE DE MEDICINA DE RIBEIRÃO PRETO}

\author{
TERMO DE CONSENTIMENTO LIVRE E ESCLARECIDO \\ (Grupo de Mulheres Mastectomizadas)
}

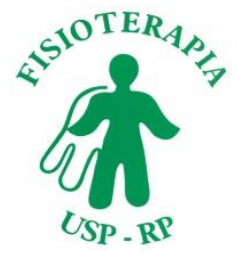

Você está sendo convidada a participar como voluntária do projeto de pesquisa "INFLUÊNCIA DA MASTECTOMIA UNILATERAL NO EQUILÍBRIO ESTÁTICO E NA MARCHA", coordenado pela Profa. Dra. Elaine C. de O. Guirro e desenvolvido pela aluna Carla Silva Perez, que tem por objetivo avaliar a marcha (maneira como andamos), a postura, o equilíbrio e os músculos do ombro de mulheres que realizaram a cirurgia para o tratamento do câncer de mama (mastectomia), como no seu caso. Este projeto tem como objetivo ajudar a compreensão dos motivos que podem levar a desequilíbrios marcha e postura inadequadas após o tratamento do câncer de mama. Após sua confirmação em participar do estudo, será agendado um horário e data combinado entre você e o pesquisador para o início das atividades. Você deverá comparecer ao REMA (Núcleo de ensino, pesquisa e assistência a mulher mastectomizada), e após atendimento será encaminhada ao Laboratório de Biomecãnica e Controle Motor (LaBioCom), para a realização da entrevista (preenchimento dos dados pessoais e avaliação física individual), onde, de acordo com os critérios estabelecidos no projeto, irá fazer parte de um dos grupos. A avaliação terá duração de aproximadamente 60 minutos. Onde a senhora deverá estar minimamente vestida, serão analisados o tamanho dos braços e algumas medidas do corpo; serão ainda realizadas marcações com bolinhas em pontos específicos do corpo (marcadores) para avaliação dos segmentos corporais e pequenos quadrados serão colocados no ombro (eletrodos), para ver a atividade do músculo. Será solicitado que a senhora ande normalmente, e depois permaneça parada até o final da avaliação (por 20 minutos).

As avaliações a serem realizadas não trarão qualquer tipo de desconforto ou risco. Se a senhora concordar em participar da pesquisa, receberá informações sobre sua maneira de andar, seu equilíbrio e sua postura.

A sua participação neste estudo é voluntária e sigilosa, sendo que os dados coletados ficarão com a orientadora do projeto em arquivo do laboratório, cujo acesso é restrito aos pesquisadores. É seu direito não mais participar quando desejar, sem que isso cause penalidade ou prejuízo a sua pessoa, bem como ao atendimento efetuado no REMA. O pesquisador também tem o direito de excluir seus dados deste estudo caso não participe de todas as avaliações ou pela não adequação ao objetivo desse estudo.

Com a sua participação neste estudo, fica garantido:

1. Receber resposta a qualquer pergunta ou esclarecimento a qualquer dúvida acerca dos procedimentos, riscos, benefícios, outras questões relacionadas com a pesquisa, e com o procedimento de avaliação a qual será submetida;

2. Ter liberdade de retirar o consentimento a qualquer momento e deixar de participar do estudo, sem que isso traga prejuízo à continuação do cuidado e tratamento;

3. Ter segurança de que não será identificada e que será mantido o caráter confidencial da informação; 
4. O compromisso de proporcionar informação atualizada durante o estudo, ainda que esta possa afetar sua vontade de continuar participando;

5. Que se existirem gastos adicionais, estes serão absorvidos pelo orçamento da pesquisa, e que não haverá recompensa financeira para as voluntárias que participarem do estudo.

Após ciência do exposto acima caso deseje participar do projeto de pesquisa, o documento devera ser assinado.

Ribeirão Preto, de de

\section{Nome da Voluntária}

$\mathrm{RG}^{\mathrm{o}}$

\section{Nome da Voluntária}

Data:

Data:

Nome da Coordenadora do Projeto

Nome da Pesquisadora Responsável

Assinatura da Coordenadora do Projeto

Assinatura da Pesquisadora Responsável

Para maiores informações e esclarecimentos, entre em contato com a orientadora, Profa. Dra. Elaine Caldeira de Oliveira Guirro (Tel: 3602-4584), ou com a pesquisadora responsável, Ft. Carla Silva Perez (Tel: 3234-2661) 


\section{UNIVERSIDADE DE SÃO PAULO FACULDADE DE MEDICINA DE RIBEIRÃO PRETO \\ TERMO DE CONSENTIMENTO LIVRE E ESCLARECIDO (Grupo de Mulheres Controle)}

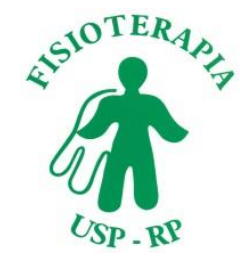

Você está sendo convidada a participar como voluntária do projeto de pesquisa "INFLUÊNCIA DA MASTECTOMIA UNILATERAL NO EQUILÍBRIO ESTÁTICO E NA MARCHA", coordenado pela Profa. Dra. Elaine C. de O. Guirro e desenvolvido pela aluna Carla Silva Perez, que tem por objetivo avaliar a marcha (maneira como andamos), a postura, o equilíbrio e os músculos do ombro de mulheres que realizaram a cirurgia para o tratamento do câncer de mama (mastectomia), bem como de mulheres sem a doença à nível de comparação, como no seu caso. Este projeto tem como objetivo ajudar a compreensão dos motivos que podem levar a desequilíbrio marcha e postura inadequadas após o tratamento do câncer. Após sua confirmação em participar do estudo, será agendado um horário e data combinado entre você e o pesquisador para o início das atividades. Após sua confirmação em participar do estudo, será agendado um horário e data combinado entre você e o pesquisador para o início das atividades. Você deverá comparecer ao local estipulado no dia agendado, bem como para a realização da entrevista (preenchimento dos dados pessoais e avaliação física individual). A avaliação terá duração de aproximadamente 60 minutos. Onde a senhora deverá estar minimamente vestida, serão analisados o tamanho dos braços e algumas medidas do corpo; serão ainda realizadas marcações com bolinhas em pontos específicos do corpo (marcadores) para avaliação dos segmentos corporais e pequenos quadrados serão colocados no ombro (eletrodos), para ver a atividade do músculo. Será solicitado que a senhora ande normalmente, e depois permaneça parada durante a avaliação (20 minutos).

As avaliações a serem realizadas não trarão qualquer tipo de desconforto ou risco. Se a senhora concordar em participar da pesquisa, receberá informações sobre sua maneira de andar, seu equilíbrio e sua postura.

A sua participação neste estudo é voluntária e sigilosa, sendo que os dados coletados ficarão com a orientadora do projeto em arquivo do laboratório, cujo acesso é restrito aos pesquisadores. É seu direito não mais participar quando desejar, sem que isso cause penalidade ou prejuízo a sua pessoa. O pesquisador também tem o direito de excluir seus dados deste estudo caso não participe de todas as avaliações ou pela não adequação ao objetivo desse estudo.

Com a sua participação neste estudo, fica garantido:

1. Receber resposta a qualquer pergunta ou esclarecimento a qualquer dúvida acerca dos procedimentos, riscos, benefícios, outras questões relacionadas com a pesquisa, e com o procedimento de avaliação a qual será submetida;

2. Ter liberdade de retirar o consentimento a qualquer momento e deixar de participar do estudo, sem que isso traga prejuízo à continuação do cuidado e tratamento;

3. Ter segurança de que não será identificada e que será mantido o caráter confidencial da informação;

4. O compromisso de proporcionar informação atualizada durante o estudo, ainda que esta possa afetar sua vontade de continuar participando; 
5. Que se existirem gastos adicionais, estes serão absorvidos pelo orçamento da pesquisa, e que não haverá recompensa financeira para as voluntárias que participarem do estudo.

Após ciência do exposto acima caso deseje participar do projeto de pesquisa, o documento devera ser assinado.

Ribeirão Preto, de de

\section{Nome da Voluntária}

$\mathrm{RG}^{\mathrm{o}}$

Assinatura da Voluntária

Data:

Data:

Nome da Coordenadora do Projeto

Nome da Pesquisadora Responsável

Assinatura da Coordenadora do Projeto

Assinatura da Pesquisadora Responsável

Para maiores informações e esclarecimentos, entre em contato com a orientadora, Profa. Dra. Elaine Caldeira de Oliveira Guirro (Tel: 3602-4584), ou com a pesquisadora responsável, Ft. Carla Silva Perez (Tel: 3234-2661) 
